\title{
SISTEMAS DEPOSICIONAIS DA CHAPADA DIAMANTINA CENTRO-ORIENTAL, BAHIA
}

\author{
AUGUSTO J. PEDREIRA*
}

\begin{abstract}
DEPOSITIONAL SYSTEMS OF THE CENTRAL-EASTERN CHAPADA DIAMANTINA, BAHIA The Mesoproterozoic sedimentary rocks cropping out in the Central-eastern Chapada Diamantina, Bahia, forming a Q-P-C (Quartzite-Pelite-Carbonate)Association, comprise twelve distinct conglomerate, sandstone and carbonate lithofacies. The lithofacies are composed of 1) conglomerates both clast and matrix supported; 2) coarse, medium, fine grained and bimodal, paraiel bedded and trough, tabular and herring bone cross bedded sandstones, 3) graded sandstones and 4) carbonates, algal laminites and dolarenites. These lithofacies are assembled into alluvial fan, fluvial, desertic, tidal flat, deltaic and marine depositional systems, alternating along the stratigraphic column. The onset of the sedimentation is continental, represented by desertic, alluvial fan and fluvial systems that progressively changes to a deltaic system, typical of a continental margin. A western source area is proposed, based on paleocurrent data. Overlying the deltaic system, occur continental and marine depositional systems with an eastern provenance because of basin tilting, suggested by paleocurrent inversion. The analysis of these systems hás allowed the reconstitution of the tectonic evolution of the region, that begins by deposition on a stable cratonic area, followed by the establishment of a foredeep.
\end{abstract}

Key-words: Depositional systems, lithofacies, Espinhaço Supergroup, Chapada Diamantina, Proterozoic.

RESUMO Os sedimentos mesoproterozóicos do Supergrupo Espinhaço que afloram na Chapada Diamantina Centro-oriental, Bahia, formando uma Associação Q-P-C (Quartzito-Pelito-Carbonato), compreendem doze diferentes litofácies. Essas litofácies são compostas de 1) conglomerados, tanto sustentados pelos clastos como pela matriz; 2) arenitos grossos, médios, finos e bimodais com estratificações plano-paralelas, cruzadas acanaladas, tabulares e espinha de peixe, marcas onduladas; 3) pelitos em geral e, 4) carbonatos com estromatólitos colunares e não-colunares, e laminitos algais. Essas litofácies se combinam em diversas associações que compõem sistemas de leque aluvial, fluvial, desértico, planície de maré, deltaico e marinho que se alternam ao longo da coluna estratigráfica. A sedimentação inicialmente é continental, representada por sistemas desértico, e de leque aluvial e fluvial, com área fonte a oeste, que transicionam para um sistema deltaico, característico de uma margem continental. Sobre o sistema deltaico, após um evento tectônico que basculou a bacia, invertendo a direção das paleocorrentes, ocorrem novamente sistemas deposicionais continentais e marinhos, provenientes de leste,. A análise desses sistemas permite reconstituir a evolução tectônica da região, que começa por deposição em uma área cratônica estável, seguida pela implantação de uma antefossa.

Palavras-chave: Sistemas deposicionais, litofácies, Supergrupo Espinhaço, Chapada Diamantina, Proterozóico.

INTRODUĈ̃̃ A Chapada Diamantina, situada na região central do Estado da Bahia (Fig. 1), é um planalto onde afloram rochas que fazem parte das coberturas mesoproterozóicas do Brasil (Delgado et al, 1994). Essas rochas, essencialmente terrígenas, foram depositadas ao longo de um intervalo do tempo geológico, de pelo menos 700 milhões de anos (Fig. 2). Devido ao seu baixo grau de metamorfismo e deformação, preservam de forma excepcional as estruturas sedimentares, de modo que é possível deduzir com apreciável grau de precisão os seus processos e ambientes de deposição originais.

O estudo dos sistemas deposicionais na Chapada Diamantina se iniciou com a publicação do trabalho de Monteiro et al. (1984), seguida dos de Souza \& Guerra (1986) e Vilas Boas et al. (1988), culminando com o Projeto Utinga-Mucugê, executado pela Companhia de Pesquisa de Recursos MineraisCPRM, cujos resultados foram publicados em 1990 (Guimarães \& Pedreira 1990, Bomfím \& Pedreira 1990, Pedreira \& Margalho 1990). No trabalho de Monteiro et al. (1984) foram analisados os sistemas deposicionais componentes do Grupo Chapada Diamantina na parte norte do domínio homónimo. Esses autores determinaram a transição de sistemas continentais para marinhos e o retorno dos sistemas continentais naquela região. Souza \& Guerra (1986) investigaram grande parte da região ocidental da Chapada Diamantina e um pequeno trecho da sua região oriental, utilizando o conceito de unidade deposicional, definido por eles como um conjunto de rochas depositado em determinado espaço, pelos mesmos conjuntos de processos, em um intervalo de tempo compreendido entre duas pausas na atuação desses processos. Esses autores dividiram o pacote sedimentar aí aflorante em oito unidades deposicionais e concluiram que todas as unidades são concordantes entre si e foram depositadas durante um único evento de abaixamento da crosta, com oscilações do nível do mar. No contexto de um trabalho mais abrangente, Pedreira et al. (1989) determinaram os ambientes de deposição do Supergrupo Espinhaço na região oriental da Chapada Diamantina e adotaram a divisão do Grupo Paraguaçu feita por Pedreira (1988) em três unidades informais: "camadas" Barra da Estiva, Ibicoara e Sincorá, as duas primeiras unidades correspondentes à Formação Mangabeira e a última à Formação Guiné (Fig. 1). Entre 1985 e 1989 a CPRM mapeou uma área de $9.000 \mathrm{~km}^{2}$ na Chapada Diamantina Oriental, para o Programa de Levantamentos Geológicos Básicos do Brasil-PLGB (Pedreira \& Margalho 1990, Bomfím \& Pedreira 1990, Guimarães \& Pedreira 1990). Esses autores interpretaram as diversas litofácies e as agruparam em sistemas deposicionais, correlacionando-os com as unidades litoestratigráficas aflorantes na Chapada Diamantina e anteriormente descritas (Fig. 2).

O presente trabalho é uma extensão das informações obtidas durante o levantamento acima citado para o restante da região centro-oriental da Chapada Diamantina (Fig. 1). Ele está baseado essencialmente na tese de doutoramento do autor (Pedreira, 1994b) complementada por informações mais recentes obtidas durante a execução de levantamentos pelo Serviço Geológico do Brasil, atual denominação da CPRM. Outros estudos de abrangência maior ou mais restritos em área, serão citados oportunamente.

DESCRIÇÃO DAS LITOFÁCIES As fácies - resultado da atuação dos processos físicos, químicos e/ou biológicos no ambiente sedimentar (Gama Jr.1989) - podem considerar tanto os aspectos litológicos (litofácies), como os paleontológicos (biofácies); no caso dos sedimentos proterozóicos 


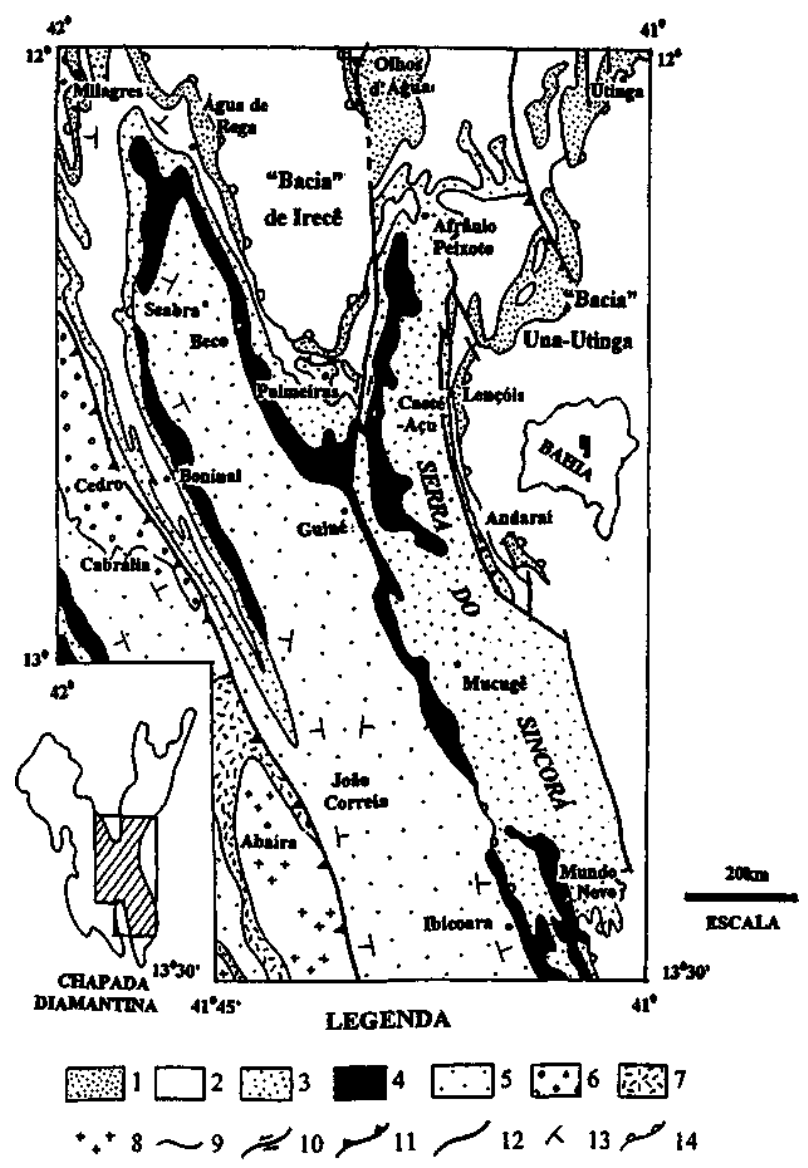

Figura l- Mapa Geológico do Super grupo Espinhaço na Chapada Diamantina Centro-oriental. Legenda: 1-Formação Morro do Chapéu: 2-Formação Caboclo; 3-Formação Tombador; 4- Formação Guiné; 5- Formação Mangabeira; 6- Formação Ouricuri do Ouro; 7- Grupo Rio dos Remédios; 8-Granito de Jussiape; 9-Contato; 10-Falha transcorrente; 11-Falha contracional; 12-Outras falhas; 13-Atitude de camada; 14-Discordância.

Figure 1 - Geologia Map of the Espinhaço Supergwup in the Central-eastern Chapada Diamantina. B-Location of the área studied in the Chapada Diamantina. Explanation: 1-Morro do Chapéu Formation; 2-Caboclo Formation; 3-Tombador Formation; 4-Guiné Formation; 5-Mangabeira Formation; 6-Ouricuri do Ouro Formation; 7-Rio dos Remédios Group: 8-Jussiape Granite; 9-Contact; 10-Tearfault; 11-Contractional fault (barbs in upper block); 12-Other faults; 13-Bedding altitude; 14-Unconformity.

do Supergrupo Espinhaço, com exceção dos laminitos algais e estromatólitos colunares da Formação Caboclo, inexistem biofácies. Na Chapada Diamantina, as formações componentes do Supergrupo Espinhaço apresentam 12 litofácies principais que se sucedem ao longo da coluna estratigráfica. $\mathrm{Na}$ figura 3 elas são mostradas juntamente com as suas granulometrias predominantes e o provável material original. Para sua determinação foram analisadas as publicações de Guimarães \& Pedreira (1990), Bomfim \& Pedreira (1990) e Pedreira \& Margalho (1990) além dos dados obtidos durante os trabalhos de campo realizados após a publicação desses trabalhos. Sob o ponto de vista interpretativo, Strand (1988) considera cada litofácies como produto de um evento deposicional individual que pode ser interpretado em termos hidrodinâmicos; as associações de litofácies por outro lado, são produto de ambientes deposicionais específicos.

Litofácies de conglomerados Conglomerados sustentados pela matriz, maciços ou gradados, afloram prin-

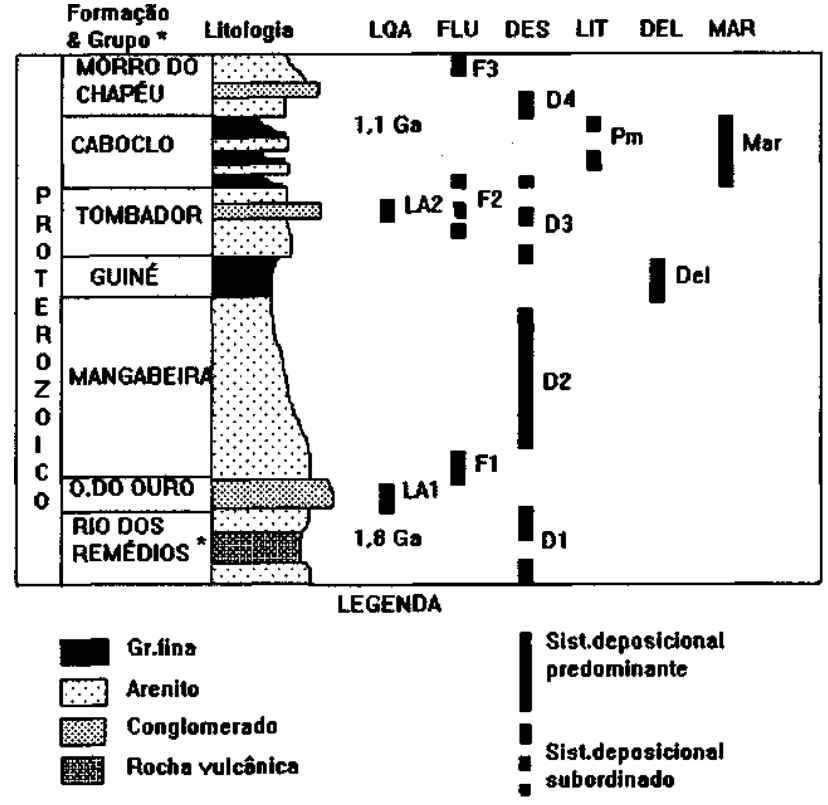

Figura 2 - Posição dos sistemas deposicionais em relação às unidades litoestratigráficas aflorantes na Chapada Diamantina Centro-oriental. Idades de acordo com Babinski et al. (1993) e Pedreira (1994b). Abreviaturas: LQA-Leque aluvial; FLU-Fluvial; DES-Desértico; LIT-Litoral; DEL-Deltáico; MAR-Marinho. LA1, LA2: sistemas de leques aluviais inferior e superior; F1, F2, F3: sistemas fluviais inferior, intermediário e superior; D1, D2, D3, D4: sistemas desérticos inferior, intermediários e superior; Pm: sistema de planície de maré; Del: sistema deltaico; Mar: sistema marinho. Figure 2 - Position of the depositional systems in relation to the lithostratigraphic units of the Central-eastern Chapada Diamantina. Ages according to Babinski et al.(1993) and Pedreira (1994b). Key; LQA-Alluvial fan; FLU-Fluvial; DES-Desertic; LIT-Littoral; DEL-Deltaic; MAR-Marine.LAl, LA2: lower and upper alluvialfan systems; F1, F2, F3: lower, intermediate and upper fluvial systems; D1, D2, D3, D4: lower, intermediate and upper desertic systems; Pm: tidal flat system; Del: deltaic system; Mar: marine system.

cipalmente na parte ocidental da área da figura 1. Também ocorrem restritamente na região de Lençóis. Na primeira região o conglomerado consiste em camadas maciças ou com estratificação grosseira, localmente apresentando espessamento das camadas em direção ao topo. Os clastos são de gnaisse, granito, quartzo de veio, xisto e rochas vulcânicas, com diâmetro variando entre 5 e $20 \mathrm{~cm}$. Na região de Lençóis os conglomerados, sustentados pela matriz, ocorrem em camadas com espessura de até $1,5 \mathrm{~m}$ e continuidade lateral muito variável. O tamanho médio dos clastos é entre 1,5 e 3,0 $\mathrm{cm}$ e o tamanho máximo não ultrapassa $20 \mathrm{~cm}$. A matriz em geral apresenta estratificação plano-paralela ou cruzada acanalada.

Conglomerados sustentados pelos clastos, maciços ou grosseiramente estratificados afloram no flanco oriental da serra do Sincorá, de Mucugê para norte e a norte de Seabra. Os clastos são de arenito friável, quartzo rosa, quartzito verde e branco, e sílex e o seu diâmetro varia entre 1 e $20 \mathrm{~cm}$, chegando a atingir até $50 \mathrm{~cm}$. Os seixos de quartzo rosa são provenientes da própria Chapada Diamantina, conforme foi observado na cidade de Lençóis (Derby 1905); os verdes e brancos são provenientes da serra de Jacobina. Uma estrutura sedimentar conspícua nesses conglomerados é o imbricamento dos clastos maiores (Fig. 6), conforme se pode 


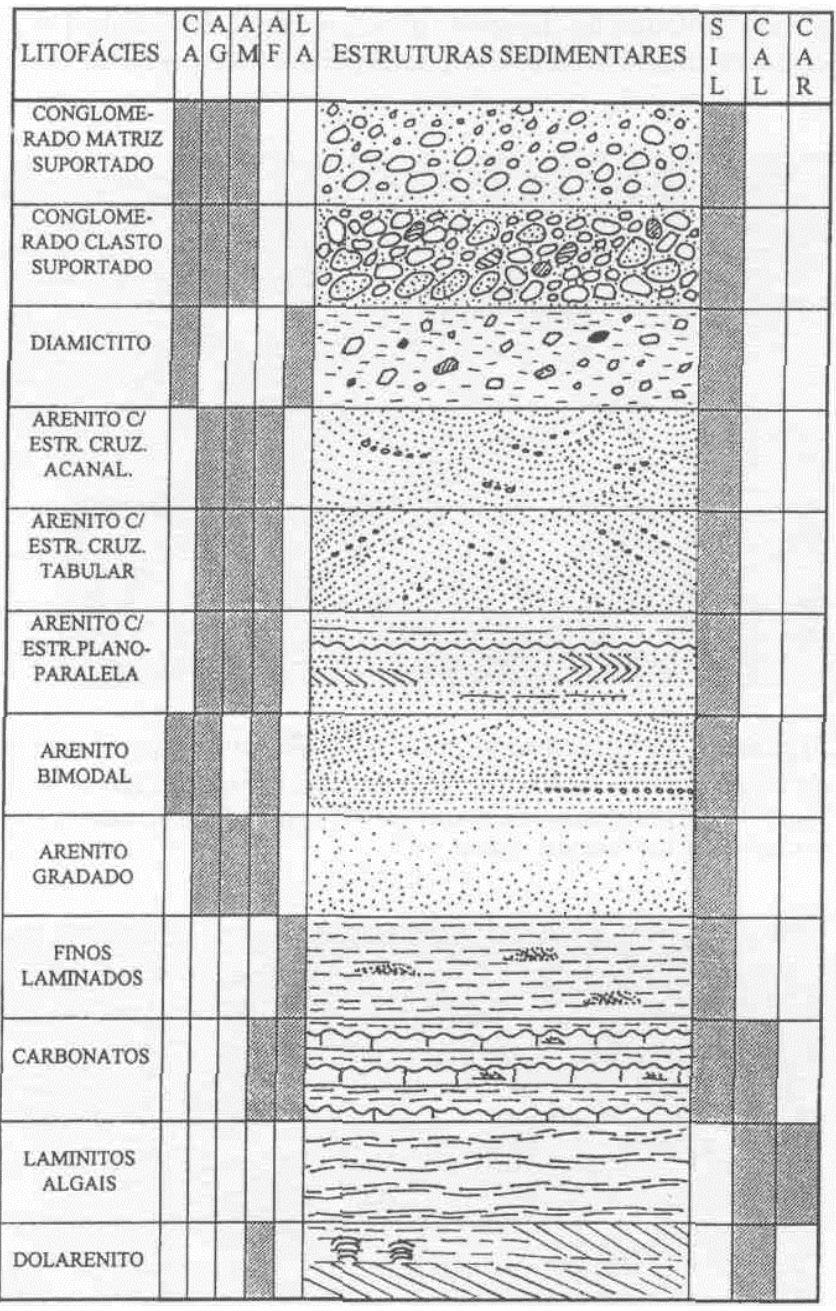

Figura 3 - Granulometria, estruturas sedimentares e composição original das litofácies componentes dos sistemas deposicionais da Chapada Diamantina Centro-oriental. Abreviaturas: CA-Cascalho; AG-Areia grossa; AM-Areia média; AF-Areia fina; LA-Lama; SIL-Sílica; CAL-Carbonato; CAR-Matéria orgânica.

Figure 3 - Grain size, sedimentary structures and original composition of the lithofacies that compose the depositional systems of Central-eastern Chapada Diamantina. Key to letters: CA-Gravel; AG-coarse grained sand; AM-Medium grained sand; AF-Fine grained sand; LA-Mud; SIL-Silica; CAL-Carbonate; CAR-Organic matter.

observar em Lençóis e no extremo norte da área. Nesse último local o conglomerado apresenta-se como uma intercalação na litofácies de conglomerados sustentados pela matriz.

Foram encontrados diamictitos apenas em uma camada intercalada em argilitos a leste de Boninal. Trata-se de um conglomerado sustentado pela matriz, com seixos de diâmetro máximo de $5 \mathrm{~cm}$. Os seixos são em geral de quartzito e a camada tem cerca de $2 \mathrm{~m}$ de espessura.

Litofácies de Arenitos Arenitos com estratificação cruzada acanalada são uma das litofácies predominantes na Chapada Diamantina Centro-oriental. Afloram desde a sua parte setentrional dezoito quilómetros a oeste de Utinga, até os arredores de Mucugê e na região de Novo Acre-Mundo Novo-Ibicoara.

Os arenitos são de coloração rósea ou acinzentada e têm granulação média a grossa ou bimodal (grossa e muito fina, sem granulometria intermediária). A geometria externa dos corpos é em camadas ou lenticular e às vezes mostram seixos dispersos (Fig. 3). Os conjuntos de estratificação cruzada medem de 10 a $50 \mathrm{~cm}$ de espessura. Quando são bimodais os conjuntos de estratificação cruzada podem atingir até mais de $1 \mathrm{~m}$ de espessura e apresentam estruturas como queda e fluxo de grãos, isto é, a granulometria distribui-se em níveis de uns poucos grãos de espessura dentro dos quais ocorrem lentes de espessura centimétrica com gradação inversa. Na maioria dos casos apresentam matriz caolínica.

Da mesma forma que os arenitos com estratificação cruzada acanalada, os com estratificação cruzada tabular também são abundantes na área do estudo. Os arenitos têm coloração predominante rosada, ocorrendo também nas cores acinzentada, avermelhada e branco. Podem ser seixosos e muitas vezes contêm feldspato e mica. A sua granulometria varia entre grossa e fina, podendo também ser bimodais, com grãos foscos. Esses arenitos quando são bimodais, na região de Ibicoara, têm estratificação cruzada do tipo Xi de Allen (1963). Nos conjuntos da estratificação cruzada verifica-se então a presença de lâminas com uns poucos grãos de espessura e granulometria grossa e fina sem termos intermediários, e matriz caolínica.

Arenitos com estratificação plano-paralela ocorrem nos mesmos locais que as litofácies de arenito anteriormente descritas e de um modo geral estão subordinados a elas, separando conjuntos de estratificação cruzada. A sua coloração é rosa, avermelhada ou marrom. A granulação é fina a média e a seleção boa a regular. A matriz, argilosa ou micácea, possui sericita ou illita. A geometria dos arenitos geralmente é tabular, em camadas de espessura variável entre 10 e $60 \mathrm{~cm}$. As estruturas sedimentares mais comuns são marcas onduladas no topo de algumas camadas, estratificações cruzadas de baixo ângulo e do tipo espinha de peixe (Fig. 3).

Existem alguns afloramentos de arenitos maciços a norte do paralelo 12 30' e na serra do Bastião, a oeste de Boninal. São arenitos rosados, amarelados ou cinza claro com matriz feldspática e palhetas de mica branca, granulação média e seleção boa a regular. A sua geometria externa é de lobos sigmoidais com marcas onduladas no topo e as estruturas internas porventura existentes foram destruídas por fluidização.

Foram encontrados arenitos gradados apenas na serra do Bastião e no extremo norte da área. No primeiro local são arenitos conglomeráticos com gradação normal e no segundo são camadas de base deformada, cuja granulometria diminui para o topo.

Litofácies de Granulação Fina Finos laminados possuem ampla distribuição na Chapada Diamantina Centro-oriental, ocorrendo desde a região de Água de Rega a noroeste, até Mundo Novo a sudeste. As suas tonalidades variam entre o esbranquiçado e lilás, passando por creme, rosa, avermelhado e até cinza ou esverdeado. Esses pelitos podem conter níveis contínuos ou lenticulares de silte micáceo, e frequentemente são encontradas neles palhetas de sericita, muscovita ou biotita, além de grânulos de quartzo ou grãos de areia dispersos na matriz argilosa. As estruturas sedimentares mais comuns nessa litofácies são laminações plano-paralelas, lenticulas de areia formando estratificação do tipo wavy \& linsen (Fig. 3) e marcas onduladas. As camadas geralmente são lateralmente contínuas e a sua espessura raramente atinge um metro.

Finos maciços são de ocorrência extremamente restrita, sendo encontrada apenas como níveis intercalados na litofácies anteriormente descrita. Trata-se de argilitos rosa, maciços, em camadas lateralmente continuas com espessura em torno de $10 \mathrm{~cm}$. Arenitos muito finos ou sílticos, maciços, formando camadas com espessura em torno de $60 \mathrm{~cm}$ com base deformada são encontradas $7,8 \mathrm{~km}$ a sudeste da Água de Rega. 
Litofácies carbonáticas ocorrem na cidade de Boninal, $13 \mathrm{~km}$ a norte da mesma cidade e $8 \mathrm{~km}$ a sudeste de Milagres. Em Boninal consiste em pequenos afloramentos de calcário maciço azulado e laminitos algais. A norte de Boninal os laminitos algais parecem estar silicificados. Os melhores afloramentos estão situados a sudeste de Milagres onde a litofácies consiste em calcarenitos e margas interacamados. Os calcarenitos estão em camadas de $5 \mathrm{~cm}$ com marcas onduladas no topo com $30 \mathrm{~cm}$ de separação das cristas, e laminação cruzada interna (Fig. 2). No outro local, que fica próximo à fazenda Sarpa (oeste da cidade de Utinga), as rochas são dolarenitos com estruturas sedimentares tais como estratificações plano-paralelas e cruzadas tabulares.

SISTEMAS DEPOSICIONAIS Um sistema deposicional é definido como uma unidade tridimensional constituida por uma associação de fácies específica, gerada por processos sedimentares atuantes nos ambientes de uma mesma província fisiográfica ou geomorfológica (Fischer \& McGowen 1967, apud Gama Jr.,1969). Na região centro oriental da Chapada Diamantina, os sistemas deposicionais se sucedem ao longo da coluna estratigráfica (Fig. 2). Embora um único sistema deposicional (associação de litofácies) possa reunir total ou parcialmente sedimentos de duas ou mais formações (Gama Jr.,1989), na Chapada Diamantina Centrooriental isto não acontece. Nessa região cada formação é integrada ou apenas por um sistema deposicional ou por mais de um, conforme mostra a figura 2.

\section{Sistemas de Leques Aluviais (LQA) DESCRIÇÃO}

Os sistemas de leques aluviais compreendem essencialmente conglomerados polimíticos. No sistema LA1 os clastos são subarredondados e compostos de quartzo de veio, rochas sedimentares, rochas vulcânicas, gnaisses, granito e xisto (Fig.4).Seus diâmetros variam entre $5 \mathrm{~cm}$ na região a sudeste de Cedro e $20 \mathrm{~cm}$ entre essa localidade e Boninal. O conglomerado é sustentado pela matriz, que é composta por arenito grosso, seixoso, com marcas onduladas no topo das camadas ou com estratificação cruzada. No sistema LA2 os clastos são de quartzito verde e branco, arredondados, com diâmetro médio de $6 \mathrm{~cm}$, e compostos de arenito rosa. Esses últimos são subarredondados e o seu diâmetro médio é de $20 \mathrm{~cm}$.

Os conglomerados do sistema LA2 são associados a arenitos médios ou bimodais com estratificação plano-paralela e cruzada, tabular, acanalada e de baixo ângulo, que possuem níveis de conglomerado com seixos de diâmetro centimétrico. $\mathrm{O}$ sistema ocorre em dois níveis diferentes: o superior em Lençóis (Fig.5) e o inferior cerca de $10 \mathrm{~km}$ a NNW desta cidade (Fig. 6), separados por arenitos com estratificação cruzada acanalada e de baixo ângulo ou plano-paralela, e conglomerados sustentados pelos seixos, intercalados nos arenitos.

INTERPRETAÇÃO De acordo com a nomenclatura de Abbott \& Peterson (1978) os clastos de conglomerados se dividem em: ultraduráveis(quartzito, riolito e sílex), duráveis (metarenito), medianamente duráveis ( gnaisse, granito) e fracamente duráveis(xisto). Dessa forma a assembleia de clastos no sistema LA 1 é representativa de clastos desde ultraduráveis até fracamente duráveis; no sistema LA2 ocorrem apenas clastos ultraduráveis e duráveis. Os clastos de arenito deste sistema, por serem friáveis podem entretanto ser incluídos na classe de fracamente duráveis. Ainda de acordo com Abbott \& Peterson (1978) a associação entre clastos ultraduráveis e fracamente duráveis, de litologias representativas da área-fonte, indica relevo íngreme e clima árido, além de curta distância de transporte. A presença de clastos imbricados e de níveis de arenito em diversos afloramentos do sistema LA2, indicaria o seu transporte por água e assim, o seu modelo seria semelhante ao modelo Scott de Miall (1978). No modelo Scott a sedimentação se faz na porção mediana ou distal de leques aluviais. Pedreira (1994a) inter- pretou a mistura de clastos de diversas fontes do sistema LA2, como resultado da erosão de sedimentos transportados sobre

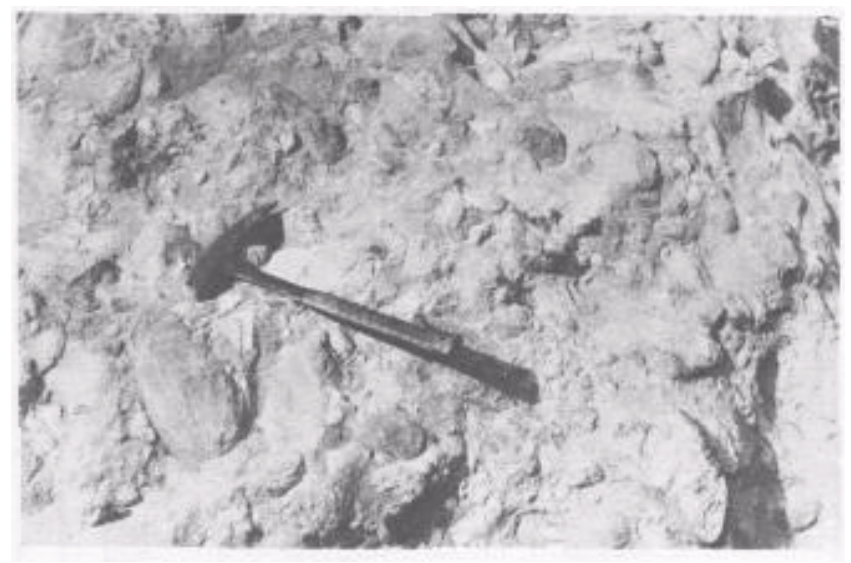

Figura 4 - Conglomerado polimítico da Formação Ouricuri do Ouro, a leste de Cedro. Sistema deposicional LA1,

Figure 4 - Polymitic conglomerate of the Ouricuri do Ouro Formation, east of Cedro.LA 1 depositional system.

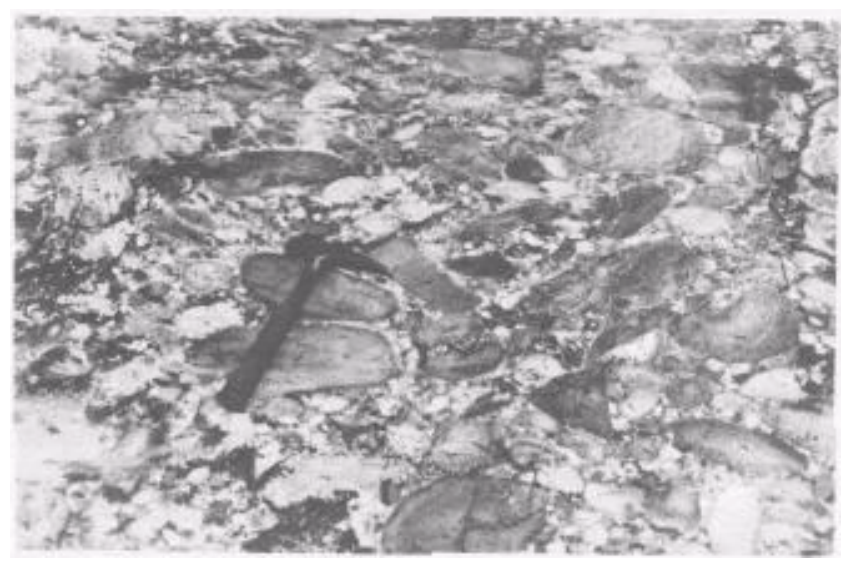

Figura 5 -Conglomerado polimítico da Formação Tombador em Lençóis. Sistema deposicional LA2.

Figure 5 - Polymitic conglomerate of the Tombador Formation in Lençóis. LA2 depositional system.

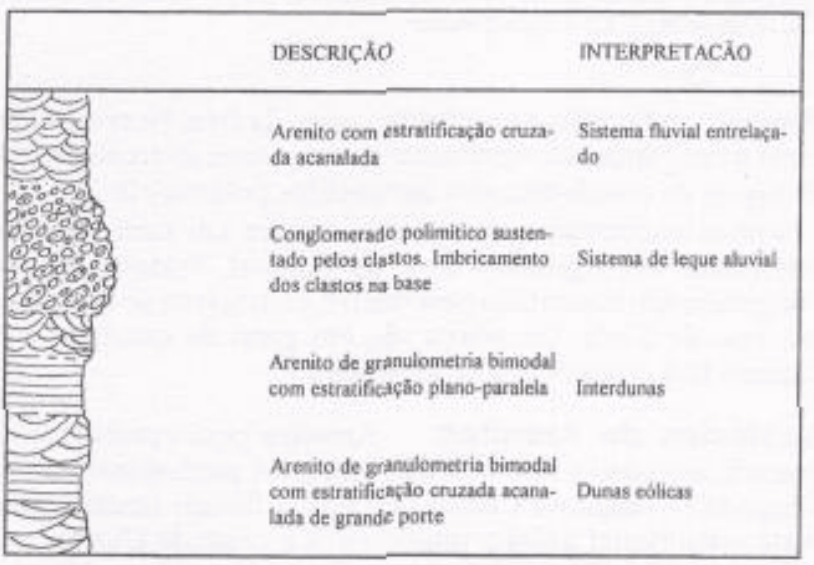

Figura 6 - Coluna estratigráfica esquemática do sistema deposicional LA2 na rodovia BR-242, a noroeste de Lençóis. Espessura aproximada, $50 \mathrm{~m}$.

Figure 6 - Schematic stratigraphic column of the LA2 depositional system in BR-242 highway, northwest of Lençóis. Approximate thickness, 50meters. 
rampas. No sistema LA2, as paleocorrentes medidas indicam área-fonte a leste.

Sistemas Fluviais (FLU) DESCRIÇÃO Os sistemas fluviais ocorrem próximo à base da coluna estratigráfica $(\mathrm{Fl})$, repetindo-se diversas vezes ao longo da parte média a superior da mesma (F2) e também dominam a sua parte mais superior (F4), conforme pode ser visto na figura 2.

A sudoeste de Mucugê (Fig. 1) as litofácies do sistema fluvial consistem em arenito rosa de granulação grossa com grãos subarredondados, bem selecionados e com alguns grãos quebrados. As camadas têm laminação plano-paralela ou estratificação cruzada de baixo ângulo. Os seixos dos conglomerados são compostos por quartzo de veio e arenito ferruginoso. Camadas de arenito fino de cor rosa, com estratificação plano-paralela, mostram no topo marcas onduladas linguóides (Fig. 7). Esse sistema fluvial continua daí para sul em direção a Ibicoara. A oeste dessa última cidade ele é representado por arenito rosa de granulação média e boa seleção, com estratificações cruzadas acanaladas em conjuntos com $0,5 \mathrm{~m}$ de.espessura Esses arenitos são superpostos por uma camada delgada da mesma rocha com granulometria bimodal e por conglomerados sustentados pela matriz com seixos de quartzito e quartzo de veio. Acima dos conglomerados a sequência de arenitos se repete, terminando por uma camada de argila vermelha (Fig. 8). Três quilômetros a norte de Ibicoara, a sequência fluvial consiste em arenito rosa com intercalações finas de argila lilás com cerca de $5 \mathrm{~cm}$ de espessura, marcando os planos de estratificação, aos quais estão associados pequenos seixos arredondados. Os arenitos também possuem intraclastos de argila. No topo das camadas, ocorrem lineações de partição e estruturas de dimensões centimétricas com contorno elíptico em planta e laminação cruzada interna, interpretadas como ondulações cavalgantes.

As figuras 9 e 10 representam as associações de litofácies fluviais do sistema deposicional F2. Na rodovia Andaraí-Mucugê a sequência começa por arenitos com estratificação cruzada acanalada superpostos por camadas da mesma rocha com estratificação plano-paralela. Algumas camadas tem estratificação cruzada tabular. Acima do cemitério de Mucugê (Fig. 9) a seção começa por arenitos cinza friáveis com matriz argilosa, que são superpostos por arenitos brancos com estratificação plano paralela ou cruzada de baixo ângulo e marcas onduladas com RI (ripple index) $=6$ (Tucker 1982). Os arenitos com estratificação plano-paralela se repetem ao longo da seção sempre associados a arenitos com estratificação cruzada acanalada. Existem também camadas com estratificação cruzada tabular, nas quais as mais antigas mostram evidências de escavação pelas mais novas. A seção termina por arenitos conglomeráticos e conglomerados com granocrescência positiva.

No morro do Pai Inácio (nordeste de Palmeiras) na base do sistema deposicional $\mathrm{F} 2$, as camadas com estratificação cruzada acanalada ou tabular são separadas por níveis de argila e silte com estratificação lenticular e marcas onduladas nas partes sílticas. A leste dessa localidade ocorre novamente a associação entre arenitos com estratificação cruzada acanalada, tabular e estratificação plano-paralela, além de conglomerados.

A oeste de Boninal, e norte de Mucugê no rio Combucas, o sistema fluvial F2 é representado por conglomerados e arenitos. Os conglomerados se dispõem em bancos com espessura em torno de $1 \mathrm{~m}$ com seixos de quartzito branco ou verde, bem arredondados e imbricados. No rio Combucas nota-se a passagem lateral para arenitos conglomeráticos rosa. Finalmente, a oeste de Boninal, os seixos estão em camadas com cerca de um metro de espessura alternando-se com arenitos de granulação grossa com estratificação cruzada acanalada ou difusa, dificultando sua identificação. Nesses conglomerados é comum o imbricamento dos seixos.
No sistema deposicional F3 além dos arenitos também ocorrem conglomerados, tanto sustentados pelos seixos quanto com estratificação cruzada acanalada.

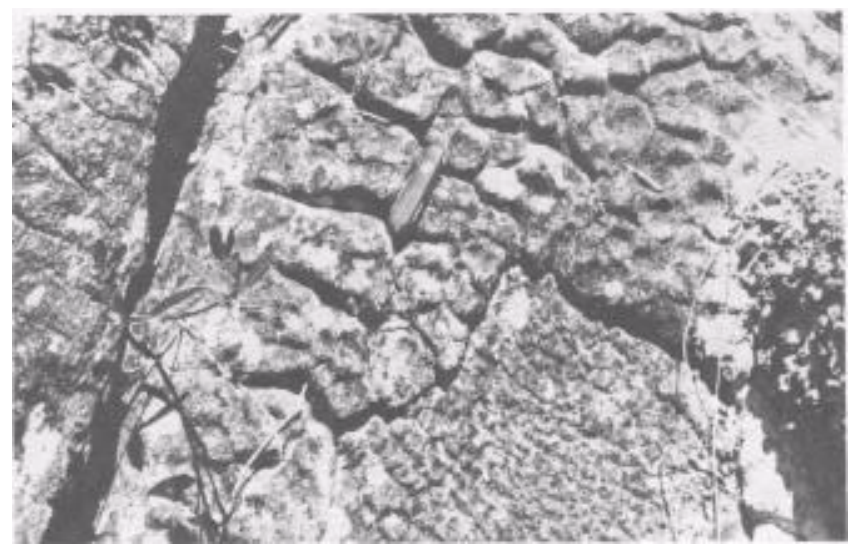

Figura 7 - Marcas onduladas linguóides em arenitos da Formação Mangabeira, a sudoeste de Mucugê. Sistema deposicional F1.

Figure 7 - Linguoid ripples in sandstone of the Mangabeira Formation, southwest of Mucugê. F2 depositional system.

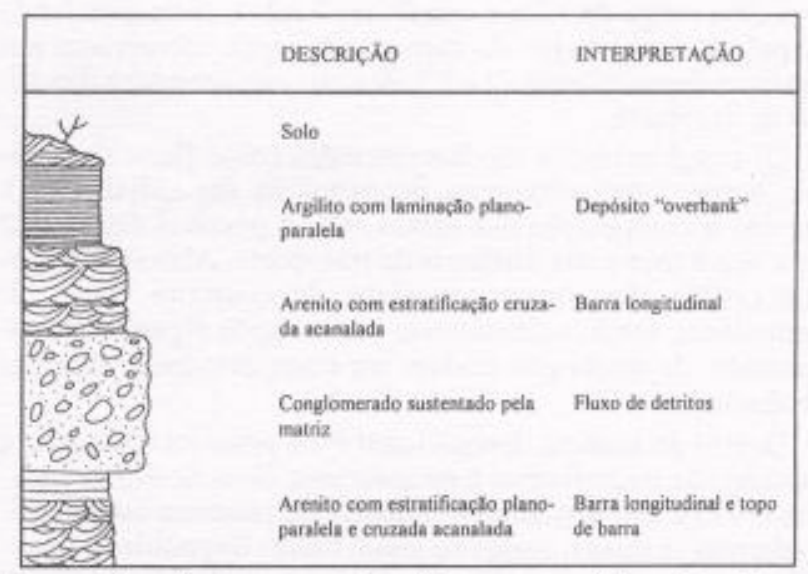

Figura 8 - Coluna estratigráfica esquemática do sistema deposicional Fl a oeste de Ibicoara. Sem escala.

Figure 8 - Schematic stratigraphic column of the Fl depositional system west of Ibicoara. Not to scale.

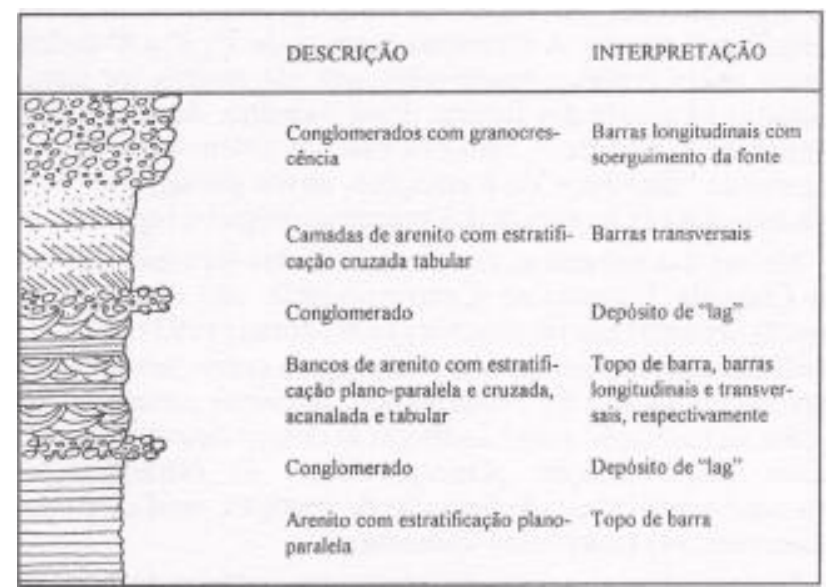

Figura 9 - Coluna estratigráfica esquemática do sistema deposicional F2 na cidade de Mucugê. Espessura aproximada, $130 \mathrm{~m}$.

Figure 9 - Schematic stratigraphic column of the F2 depositional system in the town of Mucugê. Approximate thickness, 130 meters. 


\begin{tabular}{|c|c|c|}
\hline & DESCRIÇÃO & INTERPRETACAAO \\
\hline 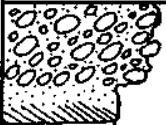 & $\begin{array}{l}\text { Conglomerados com essinati- } \\
\text { ficactio grosseira, imbricafilo } \\
\text { dos clastos }\end{array}$ & Barras longitudinais \\
\hline $\begin{array}{l}E \infty \\
0\end{array}$ & $\begin{array}{l}\text { Arenitos com estratificaģlo } \\
\text { plano-paralela e cruzada, } \\
\text { tabular e acanalada }\end{array}$ & $\begin{array}{l}\text { Topo de barm, barms irans- } \\
\text { versais e longitudinais }\end{array}$ \\
\hline
\end{tabular}

Figura 10 - Coluna estratigráfica esquemática do sistema deposicional F2 10km NNW da cidade de Lençóis. Espessura aproximada, $37 \mathrm{~m}$.

Figure 10 - Schematic stratigraphic column of the F2 depositional system $10 \mathrm{~km}$ NNW of the town of Lençóis. Approximate thickftess, 37 meters.

INTERPRETAÇÃO Nas sequências representadas nas figuras 8,9 e 10 é comum a associação entre arenitos com estratificação plano-paralela e cruzada acanalada. Essa associação é interpretada como barras longitudinais superpostas por depósitos de topo de barra. No topo desses depósitos podem ocorrer marcas onduladas linguóides (Fig. 7), formadas em água rasa com alta velocidade de fluxo (Tucker 1982). As estratificações cruzadas tabulares são formadas em rios com carga de leito e canais profundos, correspondendo ao próprio canal do rio. As camadas de argila encontradas nos sistemas deposicionais F1e F2, devem corresponder a depósitos de overbank.

Os conglomerados são interpretados como fluxo de detritos, barras longitudinais ou depósitos de lag (Miall, 1977). Devido à composição dos seixos, não é possível determinar com segurança a sua distância de transporte. Abbott \& Peterson (1978) classificam os seixos de quartzito como ultraduráveis, sendo praticamente inertes após algum arredondamento, de modo que podem ser transportados a enormes distâncias.

Dentro do sistema deposicional F2 é possível distinguir a presença de microformas e mesoformas, do conceito de Jackson (1975), isto é, marcas onduladas de pequena escala (microformas) e dunas, ondas de areia, barras linguóides e transversais (macroformas). Dentro do conceito de Miall (1988), podem ser distinguidas com segurança a nível dos estudos efetuados na Chapada Diamantina Centro-oriental, superfícies limitantes de $1^{\mathrm{a}}$ ou $5^{\mathrm{a}}$ ordem, que marcam respectivamente os limites entre conjuntos de estratificação cruzada ou são delineadas por relevos de corte e preenchimento de lag delimitando canais. A distinção entre as de $2^{\mathrm{a}}, 3^{\mathrm{a}}$ e $4^{\mathrm{a}}$ ordem baseia-se em critérios muito sutís, que não podem ser representados na escala das figuras deste trabalho. As superficies limitantes de $6^{\text {a }}$ ordem, com extensão de ordem quilométrica separando "membros"de formações, talvez possam ser identificadas apenas na escala dos mapas geológicos regionais.

Muitas das estruturas características dos sistemas fluviais da Chapada Diamantina Centro-oriental, são comparáveis com as descritas por Bhattacharyya \& Morad (1993) na Dhandraul Sandstone Formation, interpretada como um depósito fluvial entrelaçado do Proterozóico. Algumas estruturas descritas na formação acima análogas às desses sistemas são: (1) fácies de laminação plano-paralela; (2) estratificações cruzadas acanaladas; (3) lineação de partição, mud chip conglomerate; (4) superfícies limitantes.

Essas analogias permitem interpretar as fácies fluviais do Supergrupo Espinhaço como sistemas fluviais entrelaçados. A ausência generalizada de conglomerados no sistema deposicional F 1 caracteriza o seu ambiente de deposição como semelhante ao modelo South Saskatchewan de Miall (1978). Já o sistema deposicional F2 se assemelha ao modelo Donjek do mesmo autor. A grande extensão dos depósitos, perpendicularmente a direção do transporte de acordo com Rust (1978) é um indício importante da deposição em uma planície aluvial. Esses depósitos, segundo o mesmo autor, foram mais abundantes anteriormente ao aparecimento da vegetação sobre a Terra.

\section{Sistemas Desérticos (DES) DESCRIÇÃO Siste-} mas desérticos ocupam grande parte da porção média da Chapada Diamantina Centro-oriental e ocorrem subordinadamente no restante dela (Fig. 2).

O sistema Dl é caracterizado por camadas centimétricas de arenitos com granulometria bimodal associadas a níveis de argila com lentículas de areia fina. Devido aos cisalhamentos paralelos ao Lineamento Barra do Mendes-João Correia (Jardim de Sá et al 1976) que se prolonga da última localidade para NNW, não é possível observar estruturas sedimentares nessas rochas. Tais estruturas estão bem definidas a sudoeste da área mostrada na figura 1 , onde consistem em estratificações plano-paralelas em camadas com cerca de $5 \mathrm{~cm}$ de espessura, que separam conjuntos de estratificação cruzada acanalada cuneiforme com espessura de 18 a $20 \mathrm{~cm}$.

As associações de fácies e estruturas sedimentares mais características de desertos se encontram no sistema deposicional D2, de maior espessura. Na região a sudoeste de Ibicoara os arenitos são de granulação média a fina com matriz caolínica; os grãos são de quartzo e feldspato. As estruturas sedimentares predominantes nesses arenitos são estratificações cruzadas acanaladas em conjuntos de espessura variável entre 0,8 e $1,2 \mathrm{~m}$ que se truncam entre si. Marcas onduladas, quando existem, tem cristas paralelas ao mergulho das sequências frontais das estratificações cruzadas. Em alguns lugares esses conjuntos são separados por superfícies marcadas por níveis de argila com cerca de $20 \mathrm{~cm}$ de espessura, suborizontais. Os conjuntos de estratificação cruzada subordinados a essas superfícies também são separados por níveis semelhantes, mais delgados. Próximo ao limite meridional da área, na rodovia B A-142, uma dessas superfícies horizontais é encontrada truncando estratificações cruzadas acanaladas com cerca de $17 \mathrm{~m}$ de largura e $2,8 \mathrm{~m}$ de desnível entre a superficie horizontal e o conjunto mais inferior da estratificação cruzada.

Em uma faixa de direção NNW-SSE situada na mesma região, afloram arenitos bimodais com estratificação cruzada tabular do tipo Xi de Allen (1963), descritos por Pedreira (1989). Nesses arenitos encontram-se evidências de sedimentação sob condições de umidade, constantes de níveis centimétricos compactos de estratificação cruzada tabular, contrastando com o restante do afloramento, mais friável. Outra evidência de umidade é a presença de seixos de areia nas sequências frontais de estratificação cruzada.

$\mathrm{Na}$ cidade de Seabra o sistema deposicional D2 consiste em arenitos de granulometria média com lentes de granulometria mais grossa, granocrescentes, produzidas por fluxo de grãos. As camadas de arenito têm internamente estratificações cruzadas acanaladas e tabulares ou plano-paralelas, cujos planos são determinados por microgradações. Essas camadas são separadas por níveis de argila branca com cerca de $15 \mathrm{~cm}$ de espessura, próximos aos quais os arenitos têm marcas onduladas e provavelmente ondulações cavalgantes (Fig. 11). Logo a leste desse afloramento e estratigraficamente acima dele, está outro afloramento de características distintas (Fig. 12). Os arenitos aí são bimodais formando linhas com uns poucos grãos de espessura e mostram estratificação cruzada acanalada cuneiforme. Separando os conjuntos de estratificação cruzada, existem superfícies marcadas por níveis de argila. As superfícies são suborizontais e três delas se prolongam por todo o afloramento. A mais inferior mede $25 \mathrm{~cm}$ de espessura e consiste em argila com lentículas de areia. As duas superiores são mais delgadas e parecem con- 
sistir só de argila, separando conjuntos de estratificação cruzada com espessura variável entre 0,5 e 1,4m e extensão lateral entre 4 e $5 \mathrm{~m}$.

No sistema deposicional D3 as associações de litofácies consistem em arenitos brancos com estratificação planoparalela, cruzada tabular e acanalada, com raras camadas de argila e marcas onduladas. A leste de AfrânioPeixoto, a sequência começa com abundantes marcas onduladas, superpostas por estratificações cruzadas tipo Xi de grande porte e alta incidência de lentes de fluxo de grãos. Uma feição típica de desertos que ocorre no sistema deposicional D3, são níveis de pequenos seixos, de espessura centimétrica, que devem corresponder a superfícies de deflação (Fig. 13). As associaçães de litofácies do sistema deposicional D4 são muito semelhantes às do sistema deposicional D3 na rodovia BR242. Consistem também em arenitos com estratificação planoparalela e cruzada acanalada e tabular (Fig. 14). Marcas onduladas têm ocorrência localizada.

Um aspecto que diferencia o sistema deposicional D2 dos sistemas D3 e D4 é a cor da rocha: no primeiro, os arenitos são rosa ou avermelhados; nos dois últimos, são brancos ou

\begin{tabular}{|c|c|c|}
\hline & DESCRIÇÃO & INTERPRETAÇĀO \\
\hline & $\begin{array}{l}\text { Solo } \\
\text { Arenito de granulometria } \\
\text { bimodal com estratificacilo } \\
\text { plano-paralela e ondulapoes } \\
\text { cavalgantes }\end{array}$ & $\begin{array}{l}\text { Interdunas com evidéncias de } \\
\text { umidade }\end{array}$ \\
\hline 2 & $\begin{array}{l}\text { Arglitito } \\
\text { Arenito de granulometria } \\
\text { bimodal com } \\
\text { estratificaçio cnuzads uabular }\end{array}$ & Superficie limitante \\
\hline & Argilito & Superficie limitante \\
\hline Sisisy & $\begin{array}{l}\text { Arenito de gramulometria } \\
\text { bimodal com estratificacāo } \\
\text { plano-paralela }\end{array}$ & Interdunas \\
\hline
\end{tabular}

Figura 11 - Coluna estratigráfica esquemática do sistema deposicional D2 na rodovia BR-242 a oeste da cidade de Seabra. Espessura aproximada, 3,5 m.

Figure 11 - Schematic stratigraphic column of the D2 depositional system in BR-242 highway west of the town of Seabra. Approximate thickness, 3.5 meters.

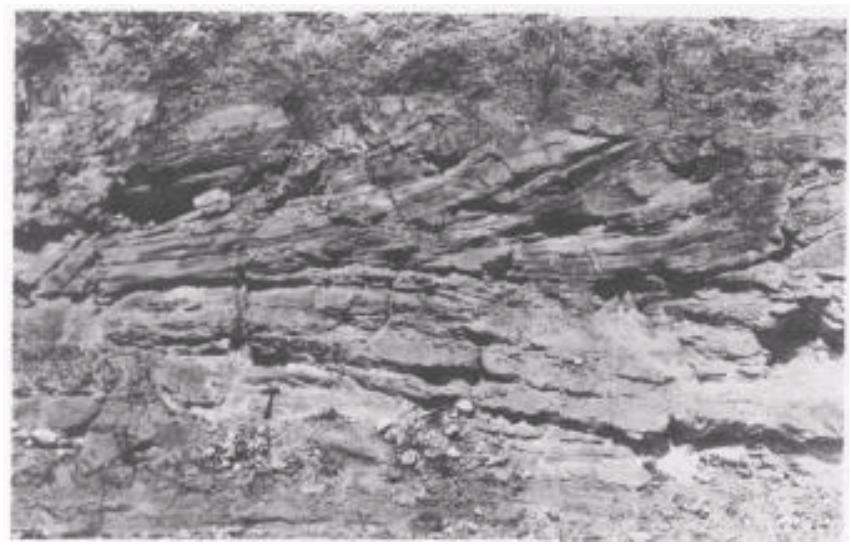

Figura 12 - Estratificação cruzada acanalada cuneiforme de grande porte em arenitos bimodais da Formação Mangabeira em Seabra. Sistema deposicional D2.

Figure 12 - Wedge-like large scale trough cross bedding in bimodal sandstones of the Mangabeira Formation in Seabra. D2 depositional system. cinza. Apenas localmente encontram-se camadas avermelhadas nesses sistemas.

INTERPRETAÇÃO Os arenitos bimodais que compreendem grande parte das associações de litofácies do sistema desértico, por serem formadas de níveis com uns poucos grãos de espessura, são interpretados como areia transportada pelo vento: os grãos maiores correspodem a vento mais forte; os menores, a vento mais fraco. A existência de grãos de feldspato misturados com grãos de quartzo é normal em clima árido. Gradzinski \& Jerzykiewicz (1974) determinaram que as areias da Formação Barun Goyot, eólicas, do deserto de Gobi na Mongólia, possuem entre 18 e $28 \%$ de feldspato.

As marcas onduladas com cristas paralelas ao mergulho das sequências frontais de estratificação cruzada, de acordo com Galloway \& Hobday (1983), são típicas de processos eólicos, bem como as desenvolvidas sobre superfícies horizontais, comum em desertos, conforme observado pelo autor na região Al Wigh, no Sahara.

Uma possível explicação para os grandes truncamentos observados entre conjuntos de estratificação cruzada, por sua

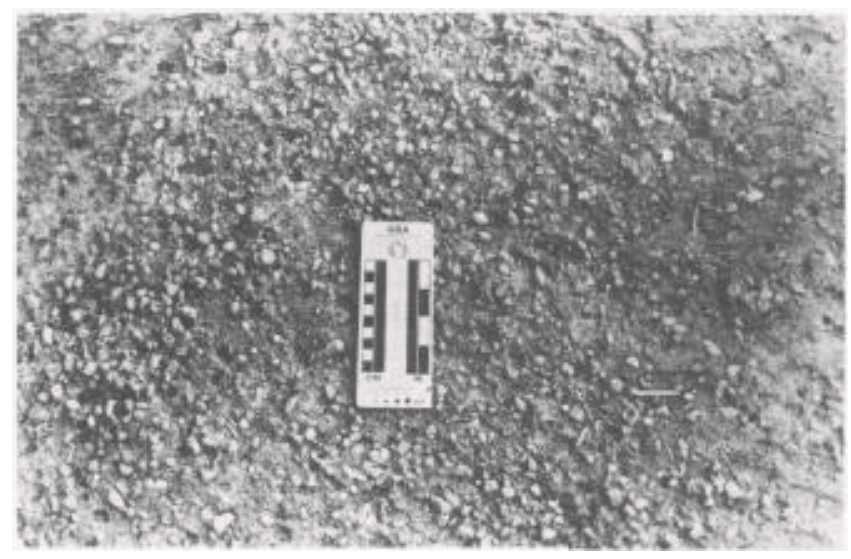

Figura 13 - Superficie de deflação na Formação Tombador, estratigraficamente acima dos conglomerados polimíticos mostrados na Figura 5. Sistema deposicional D3.

Figure 13 - Deflation surface in the Tombador Formation, stratigraphicaly above the polymitic conglomerates shown in figure 5.. D3 depositional system.

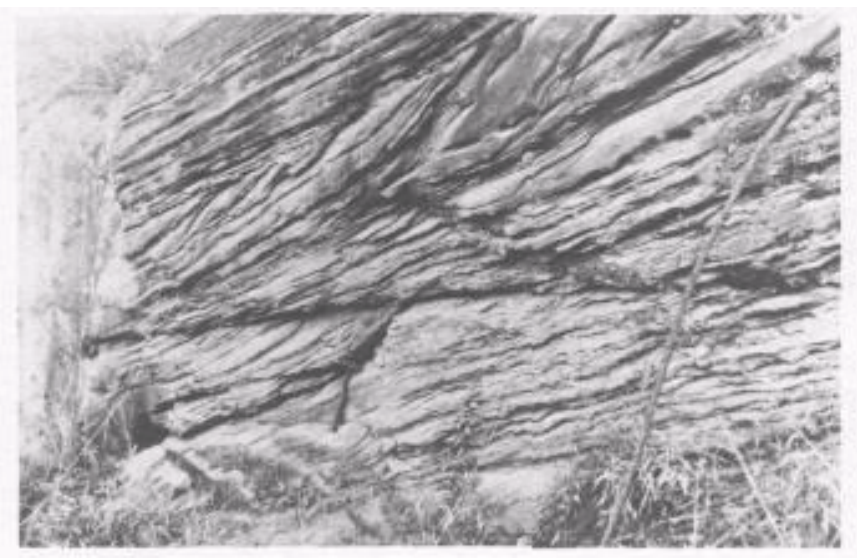

Figura 14 - Arenitos bimodais da Formação Tombador com estratificação cruzada tabular, na rodovia BR-242, $10 \mathrm{~km}$ a nordeste de Palmeiras. Sistema deposicional D3. Figure 14 - Bimodal sandstones of the Tombador Formation with tabular cross bedding, in BR-242 highway, $10 \mathrm{~km}$ northeast of Palmeiras. D3 depositional system. 
vez truncados por superfícies suborizontais com material finamente granulado (argilito) é a de que se tratem de estruturas blovv out (Gradzinski 1989, 1992), formadas pelo movimento helicoidal do vento e preenchidas posteriormente por areia.

Embora as estratificações cruzadas de grande porte do tipo $\mathbf{X i}$ possam ser indício de dunas seif, as medidas de paleovento efetuadas por Pedreira \& Margalho (1990), não indicaram isso. A comparação dos diagramas de roseta obtidos por esses autores com os de Galloway \& Hobday (1983, p.209) indicaram a presença de dunas barcanóides e talvez parabólicas. Efetivamente, Bigarella (1975) mostra que nos braços de dunas parabólicas, a estrutura das sequências frontais é do tipo Xi. O mesmo ocorre na crista de dunas estreladas (rhourd), conforme mostrado por Mc Kee (1979).

As superficies suborizontais e côncavas que separam conjuntos e tipos de estratificação cruzada devem -se enquadrar no conceito de superfícies limitantes de Brookfield (1977): as suborizontais e mais espessas seriam.de $1^{\mathrm{a}}$ ordem, separando draas, ao passo que as côncavas, seriam de $2^{\mathrm{a}}$ ordem. As de $3^{\mathrm{a}}$ ordem consistem em reativações, entre lâminas de estratificação cruzada; Kocurek (1981) interpreta as superfícies de $1^{\mathrm{a}}$ ordem como depósitos interdunas.

Os arenitos do sistema desértico têm tonalidades diferentes: os do sistema deposicional D2 geralmente são avermelhados ou róseos, e os do sistemas deposicionais D3 e D4, cinza ou brancos. De acordo com Walker (1979) a cor vermelha dos sedimentos desérticos deve-se entre outros fatores, à textura superficial dos grãos e à presença de minerais ferromagnesianos instáveis em suas rochas-fonte: os óxidos derivados daqueles, ficariam alojados nas minúsculas depressões da superfície dos grãos. A comparação de alguns dos parâmetros mencionados por aquele autor entre os três sistemas desérticos, poderia explicar essa diferença entre as tonalidades a partir de áreas-fonte de litologia distinta..

Ross (1983) discute a raridade de registros de sedimentação por processos eólicos no Precambriano. Ele argumenta que essa parte da história geológica seria particularmente adequada para a preservação desses registros, e sua aparente raridade no Proterozóico seria devida ao não reconhecimento desses sistemas, desde quando sua ocorrência em bacias intracratônicas seria uma condição favorável a sus preservação. Ao contrário do discutido por Ross (1983), no Supergrupo Espinhaço as evidências da atuação de processos eólicos são abundantes tanto na Bahia (Pedreira 1989), como em Minas Gerais (Pedreira et al 1989).

\section{Sistema de Planície de Maré (Pm) DESCRIÇÃO} O sistema de planície de maré (Pm), é bem desenvolvido a norte e sul de Boninal e nas regiões de Água de Rega, sudeste de Milagres e Olhos d'Água. Na serra do Sincorá ele ocorre em diversas faixas, das quais a mais oriental estende-se desde $20 \mathrm{~km}$ a norte de Lençóis até a sul de Andaraí. Os melhores afloramentos estão nos cortes da rodovia que liga a rodovia BR-242 a Lençóis e na própria BR-242 a oeste da cidade de Seabra (Fig. 15).

Da base para o topo essa seção é formada por camadas de arenito com marcas onduladas, seguidas por arenito maciço e por uma camada argilosa com estratificação lenticular; as lenticulas são de areia fina. Esse ciclo se repete, voltando as camadas de arenito e siltito com marcas onduladas, terminando por siltitos retrabalhados por ondas de tempestade (hummocky cross stratification). Outro local onde aflora fácies semelhante é a sudoeste de Água de Rega. Aí a associação de litofácies consiste em uma alternância de siltitos cinza com marcas onduladas no topo e ondulações cavalgantes e argilitos com estratificação ondulada e lenticular (wavy \& linsen). A sequência da rodovia entre a BR-242 e Lençóis, é semelhante a essa, sendo notáveis os exemplos de estratificação wavy \& linsen. A figura 16 exemplifica o sistema deposicional Pm a oeste da cidade de Seabra, no mesmo local da figura 15.

Ocorrências de carbonato de alguma forma relacionadas com esse sistema foram encontradas em quatro lugares: a oeste de Utinga próximo à fazenda Sarpa, em Olhos D'Água, a sudeste de Milagres e em Boninal. Próximo à fazenda Sarpa afloram dolarenitos em contato brusco com as associações de litofácies plataformal (Mar), sotoposta e eólica (D4), sobreposta. Os dolarenitos são cinza claros com estratificação plano-paralela, que às vezes torna-se ondulada, indicando estar controlada pelo crescimento de estromatólitos colunares ou tapetes de algas (Guimarães \& Pedreira 1990). Em Olhos D'Agua, a sequência é arenosa, com wrinkle marks no topo de camadas de areia que têm base canalizada assemelhando-se a gutter casts formados por tempestades. Abaixo dessas camadas ocorrem biohermas dômicos com estromatólitos colunares. As colunas medem cerca de $3 \mathrm{~cm}$ de altura por um de largura e estão muito intemperizadas. Outra seção carbonática examinada está a sudoeste de Milagres. Aí ocorrem calcarenitos com marcas onduladas assimétricas, com laminação

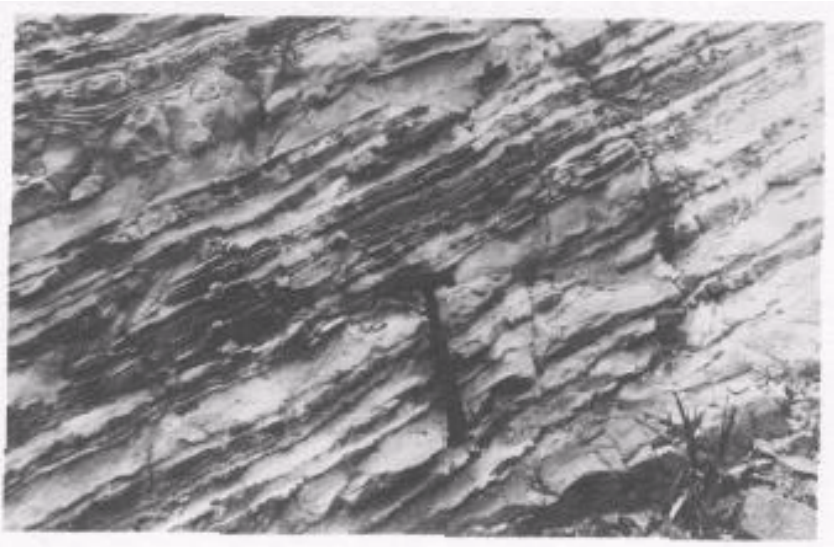

Figura 15 - Alternância de arenitos finos e argilitos na Formação Caboclo, na rodovia BR-242 $25 \mathrm{~km}$ oeste de Seabra. Notar deformação sin-sedimentar das camadas mais delgadas de areia sobre uma mais espessa, no canto esquerdo superiordafoto.SistemadeposicionalPm.

Figure 15 - Alternance of fine grained sandstones and argillite in the Caboclo Formation, in BR-242 highway $25 \mathrm{~km}$ west of Seabra. Note synsedimentary deformation of thin sandstone beds that overly a thicker one, on the upper left hand corner of the photo. Pm depositional system.

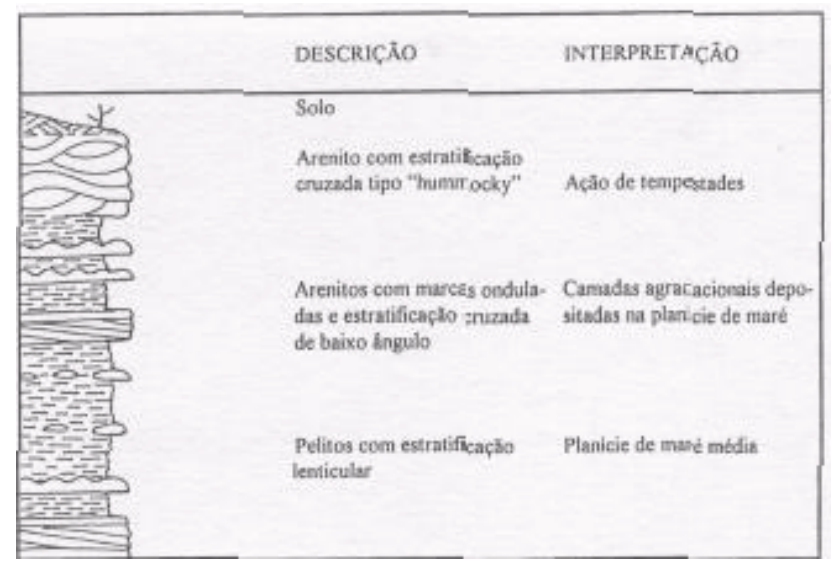

Figura 16 - Coluna estratigráfica esquemática do sistema deposicional de planície de maré na rodovia BR-242, $25 \mathrm{~km}$ a oeste da cidade de Seabra. Espessura aproximada,3 $\mathrm{m}$. Figure 16 - Schematic stratigraphic column of the tidal flat depositional system in the BR-242 highway, $25 \mathrm{~km}$ west of the town of Seabra. Approximate thickness, 3 meters. 
cruzada e pequenos estromatólitos colunares. A sul da cidade de Boninal ocorrem calcários azulados maciços e laminitos algais (Fig. 17).

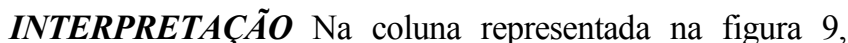
ocorrem camadas de arenito com marcas onduladas e estratificação plano-paralela e cruzada de baixo ângulo em dois níveis sucessivos. Essas camadas se assemelham às estruturas internas das barras de areia intermarés. Os pelitos com estratificação lenticular podem ser comparados à fácies heterolítica de Nikula (1988), que representa deposição na planície de maré média como aggmdational bundles (Deynoux et al. 1993); essa é uma fácies relativamente comum no sistema deposicional Pm. Finalmente no topo da seção, os arenitos com ondulações truncadas podem ser interpretados como produtos de tempestades. Esses também são processos cuja ação sobre a associação de litofácies de planície de maré é comum, uma vez que ocorre em outros locais onde aflora o sistema. Não obstante a ação de tempestades, a presença de carbonatos com estromatólitos é um indício seguro da deposição em planícies de maré o que, na área em foco ocorre pelo menos em dois níveis do sistema deposicional descrito.

Sistema Deltaico (Del) DESCRIÇAO O sistema deltaico é caracterizado pelas associações de litofácies que afloram na região a sudoeste da serra do Sincorá ao longo de sua escarpa, e no seu interior. Essa última região abrange o anticlinal do Pai Inácio, a norte e a sul de Caeté-Açu, Campo Redondo (sudeste de Ibicoara) e a área de Mundo Novo (Fig. 1). A figura 18 mostra a coluna estratigráfica dessa última área.

A base do sistema deposicional deltaico consiste em argilitos vermelhos cinza e lilazes, micáceos, com laminação planoparalela, dos quais existem bons afloramentos nos arredores de Mundo Novo (Fig. 19). Intercalados nesses pelitos ocorre uma camada de conglomerado sustentado pela matriz, (cerca de $90 \%$ de matriz e $10 \%$ de seixos) com estratificação cruzada tabular. Os seixos são de siltito lilás, bem arredondados e com cerca de $2 \mathrm{~cm}$ de diâmetro. Acima dos conglomerados, começam a aparecer níveis sílticos intercalados nos argilitos que afloram a sudeste de Ibicoara na estrada para Mundo Novo. Essa sequência marca a transição entre os pelitos da base e os arenitos do topo da sequência. Os arenitos do topo têm granulação média e muita matriz argilosa, além de níveis sílticos lilases. Esses arenitos argilosos têm estratificação plano-paralela e cruzada de baixo ângulo, marcas onduladas de crista reta e evidências de exposição subaérea constantes de mud cracks. Lateralmente os arenitos passam para corpos sigmoidais de arenito médio a fino, amarelo claro ou branco, amalgamados, com espessura em torno de $50 \mathrm{~cm}$ (Fig. 20). Na

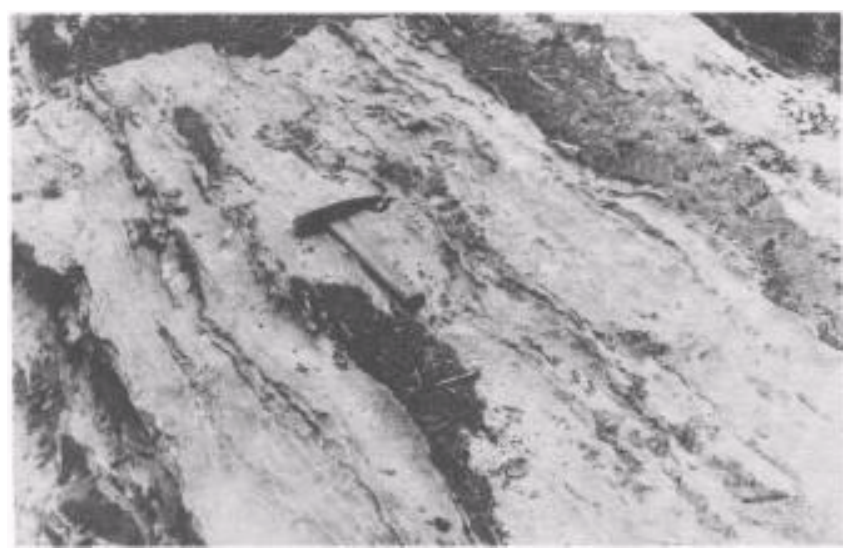

Figura 17 - Laminitos algais da Formação Caboclo a sul de Boninal. Sistema deposicional Pm.

Figure 17 - Algal laminites of the Caboclo Formation xouth of Boninal. Pm depositional system.

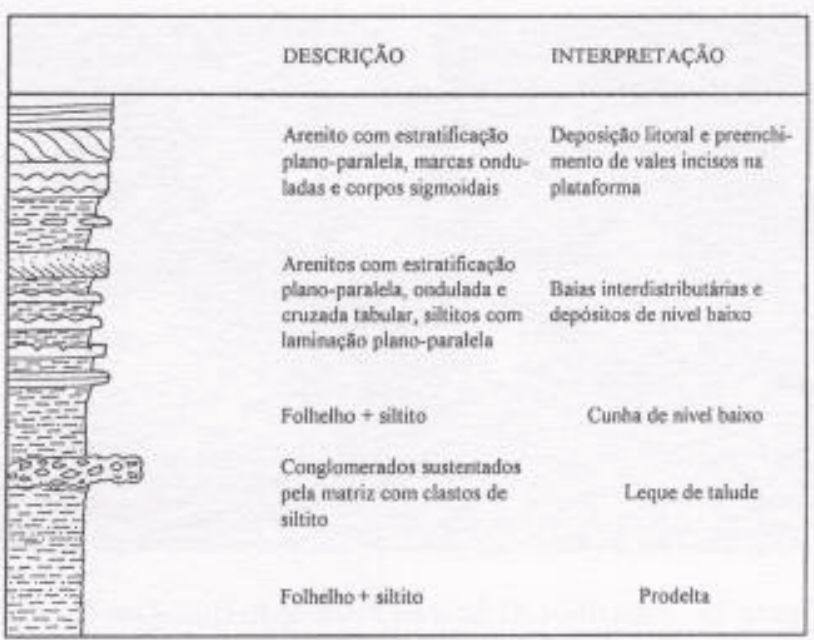

Figura 18 - Coluna estratigráfica esquemática do sistema deposicional deltaico na região de Mundo Novo. Espessura aproximada, $150 \mathrm{~m}$.

Figure 18 - Schematic stratigraphic column of the deltaic depositional system in the Mundo Novo region. Approximate thickness, 150 meters.

região do morro do Pai Inácio, a parte superior do sistema deposicional consiste em uma sequência deltaica com fluxo subaquático de areia, que distalmente (para oeste) passa a uma sequência rítmica de camadas de areia com cerca de $30 \mathrm{~cm}$ de espessura, separadas por camadas de lama ou silte. Nesse mesmo nível estratigráfico, porém mais a sul, na região de Caeté-Açu, Bomfim \& Pedreira (1990) descreveram arenitos sericíticos em corpos com geometria sigmoidal e estratificações cruzadas do tipo espinha de peixe. Na região de Guiné existe predominância de arenitos finos e siltitos com estratificação cruzada do tipo espinha de peixe, que passam a argilitos; vinte quilómetros a oeste dessa localidade, os siltitos estão em lobos amalgamados com intraclastos de argila.

INTERPRETAÇÃO Na parte inferior do sistema deposicional deltaico, a presença de litologias argilosas sem evidência de estruturas indicativas de água rasa ou exposição subaérea é interpretada com produto da deposição em águas profundas, no declive deltaico distai, sendo portanto atribuída ao prodelta. Os conglomerados intercalados neles, em outros contextos, podem ser interpretados de várias maneiras: leques aluviais, tilitos, brechas sedimentares, etc. (Tankard et al. 1982). Sua associação com os pelitos prodeltáicos entretanto, indica deposição em água profunda, como turbiditos de granulação muito grossa (Mutti 1992).

Nos arenitos do topo da coluna estratigráfica da região de Mundo Novo (Fig. 18), as estratificações plano-paralelas e cruzadas de baixo ângulo, indicam sedimentação em regime de fluxo superior. Acima daquela coluna, as marcas onduladas de crista reta evidenciam sedimentação em profundidade moderada e as mud cracks, exposição subaérea. As estratificações cruzadas do tipo espinha de peixe se formaram sob a ação de marés e os lobos amalgamados com intraclastos de lama evidenciam a ação de tempestades. Essas evidências foram interpretadas por Bomfim \& Pedreira (1990) e Pedreira \& Margalho (1990) como fácies de planície deltaica. A sua relação lateral com os arenitos de geometria sigmoidal, sugere que as fácies descritas acima pertencem às zonas interdistributárias e os arenitos sigmoidais aos canais distributários.

Recentemente, Pedreira (1995) correlacionou as litologias acima descritas com as diversas subunidades dos tratos de fácies dos sistemas deposicionais deltaicos descritos por Einsele (1992). Os argilitos inferiores e os conglomerados correspondem a uma cunha de nível baixo, que culmina com os 


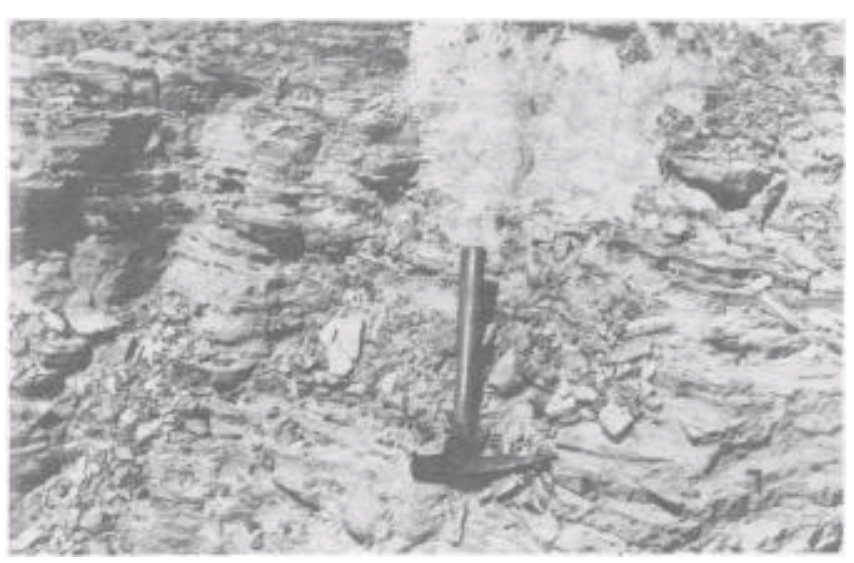

Figura 19 - Folhelhos da base da Formação Guiné em Mundo Novo. Sistema deposicional deltaico.

Figure 19 - Shales of the base of Guiné Formation in Mundo Novo. Deltaic depositional system.

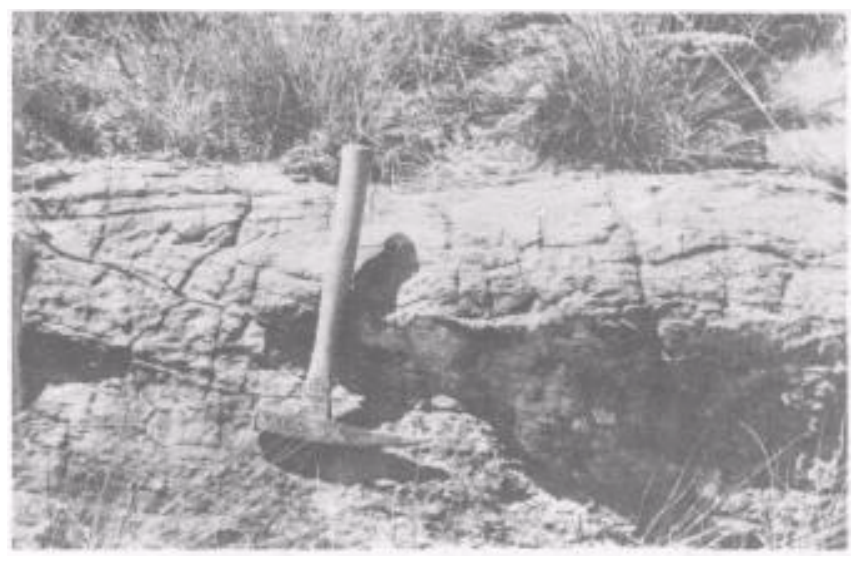

Figura 20 - Arenito com estratificação cruzada sigmoidal da Formação Guiné em Mundo Novo. Sistema deposicional deltaico.

Figure 20 - Sandstone with sigmoidal cross bedding of the Guiné Formation in Mundo Novo. Deltaic depositional system.

arenitos de estratificação cruzada sigmoidal, os quais se estendem até a região de Guiné. Os depósitos de nível alto, que ocorrem até pelo menos $20 \mathrm{~km}$ a oeste de Guiné, são encerrados pelos tempestitos.

Sistema Marinho(Mar) DESCRIÇÃO O sistema marinho plataformal aflora desde Lençóis até o limite norte da área e muito restritamente a sul de Palmeiras. A figura 21 é baseada em um afloramento nesta última região.

As camadas de areia fina a silte têm espessura entre 10 e $30 \mathrm{~cm}$ e mostram continuidade lateral (baixa lenticularidade, Clifton 1973). Próximo ao limite norte da área ocorrem níveis milimétricos de silex oolítico. A sudeste de Afrânio Peixoto, a sul de Palmeiras e na região de Olhos D'Água, essas camadas mostram ondulações truncadas (HCS) e gutter casts (J. Cândido Sales, inf. verbal 1992), que evidenciam a ação de tempestades. Os melhores afloramentos estão nessa última região. Os argilitos intercalados são vermelhos ou amarelados, possuindo em geral laminação plano-paralela; a sudeste de Afrânio Peixoto, os argilitos, além da laminação planoparalela também têm laminação cruzada e estratificação ondulada e lenticular (wavy \& linsen). Os níveis arenosos têm tendência para se espessar em direção ao topo das sequências (thickening-up).
INTERPRETAÇÃO Este sistema deposicional foi interpretado por Guimarães \& Pedreira (1990) como representativo do aumento de profundidade do mar que transgrediu sobre as rochas pertencentes aos sistemas deposicionais F2 e D3. Ele depositou-se em um ambiente abaixo das ondas normais, sujeito apenas a ondas de tempestade que deram origem às ondulações truncadas (HCS). A associação de litofácies é a equivalente distai, depositada em águas mais profundas, da associação de litofácies de planície de mareja descrita (Pm). Os níveis de silex oolítico devem estar relacionados a algum aporte de água doce: Eriksson \& Warren (1983) mencionam a presença de zonas de silicificação e dolomitização na interface água doce/água salgada em posição semelhante.

PALEOCORRENTES As áreas-fonte dos sedimentos da Chapada Diamantina já foram mencionadas em trabalhos anteriores como os de Jardim de Sá (1981) e Montes et al. (1981). A determinação sistemática das áreas-fonte dos sedimentos foi feita através de medidas de paleocorrentes. $\mathrm{Na}$ região da Chapada Diamantina mostrada na figura 1 , foram efetuadas cerca de 980 medidas: na metade oriental durante o Projeto Utinga-Mucugê (Guimarães \& Pedreira 1990, Bomfim \& Pedreira 1990, Pedreira \& Margalho 1990); na metade ocidental da área, durante diversas viagens de reconhecimento geológico No decorrer da execução do Projeto Utinga-Mucugê, foram tomadas medidas múltiplas em cada afloramento, enquanto que nas demais etapas de campo, foi apenas determinada a direção geral das paleocorrentes. A grande maioria das medidas foi tomada em feições tais como estratificações cruzadas, tanto tabulares como acanaladas, de fácies fluviais, marinhas e eólicas; as primeiras são mostradas na figura 22 . Como os mergulhos das camadas em geral não ultrapassam $25^{\circ}$,não houve necessidade de correção estrutural.

As paleocorrentes dos sistemas deposicionais Fl e Del têm caráter bimodal a polimodal, com resultantes dirigidas para leste nas fácies fluviais e no canal distributário (as três rosetas mais a sul na figura 12A), enquanto as fácies deltaicas são bimodais oblíquas ou polimodais. No sistema deposicional F2 as paleocorrentes são unimodais e dirigidas para oeste, noroeste e sudoeste - apenas um grupo de medidas tem a sua resultante no quadrante nordeste.

De acordo com Ricci-Lucchi (1985) em bacias alongadas, qualquer que seja o sistema deposicional que as preencheu, as paleocorrentes são desviadas axialmente no centro da bacia. Dos três estágios a que aquele autor se refere, ligados à evolução das paleocorrentes em uma bacia, interessam a este trabalho os estágios 1 e 3 , descritos a seguir, uma vez que o estágio 2 é intermediário entre esses e parece não estar registrado no setor em pauta da Chapada Diamantina.

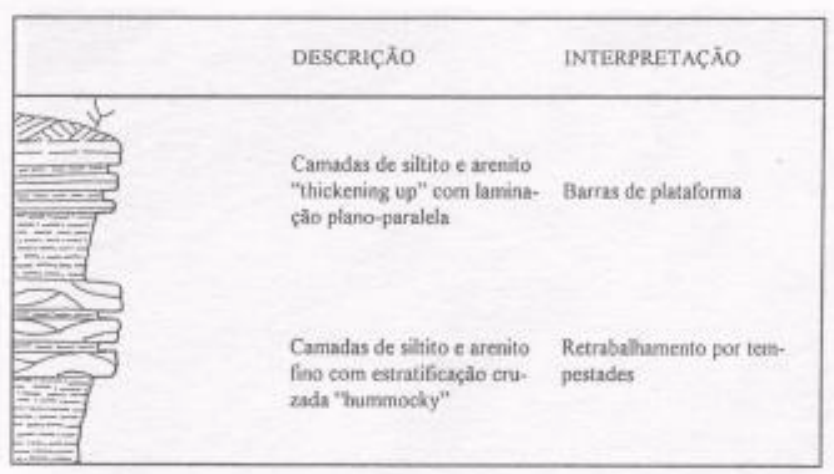

Figura 21 - Coluna estratigráfica esquemática do sistema deposicional marinho $2 \mathrm{~km}$ a sul da cidade de Palmeiras. Espessura aproximada, $5 \mathrm{~m}$.

Figure 21 - Schematic stratigraphic column of the marine depositional system, $2 \mathrm{~km}$ south of the town of Palmeiras. Approximate thickness, 5 meters. 

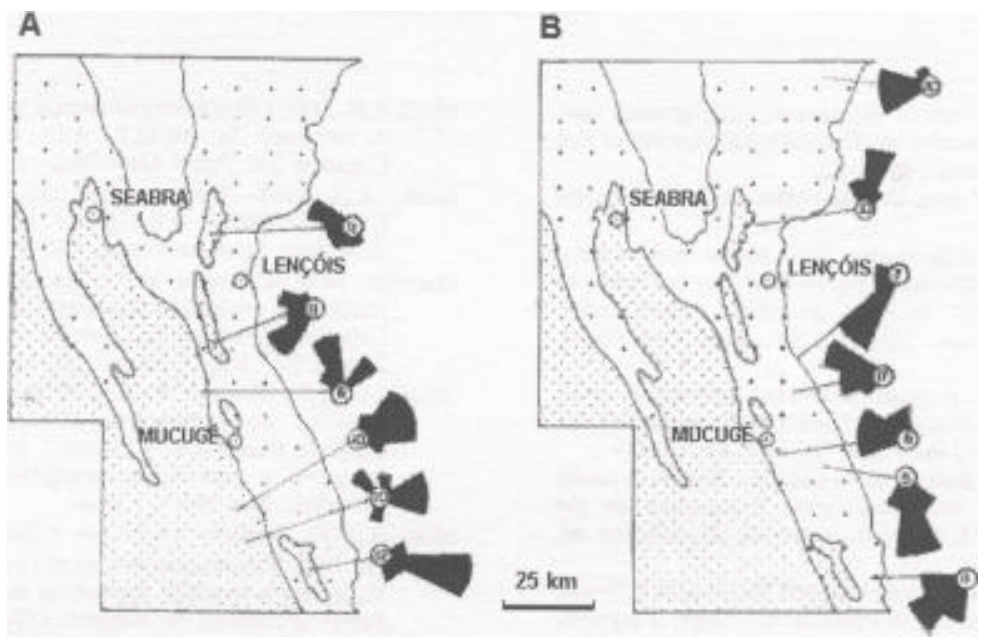

Figura 22 -Paleocorrentes fluviais e marinhas medidas na Chapada Diamantina C entro-oriental: A-Sistemas deposicionais F l e Del; B-Sistema deposicional F2.

Figure 22 - Fluvial and marine paleocurrents measured in the Central-eastern Chapada Diamantina: A-Fl and Del depositional systems; B-F2 depositional system.

No estágio 1, a margem interna da bacia seria um alto estrutural ainda submerso situado na região entre Jacobina e Contendas, imediatamente a leste da área mostrada nas figuras 1 e 22. Esse alto estrutural formaria uma barreira para o suprimento lateral trazido pelos rios. A areia só poderia alcançar a bacia a partir de uma das extremidades ou do lado oposto. Com a emersão do alto estrutural (estágio 3) o suprimento de areia na margem interna torna-se abundante. $\mathrm{O}$ efeito barreira também pode ser importante na fase precoce desse estágio, quando ainda pode haver desvio das paleocorrentes paralelamente à linha de costa. Com o desenvolvimento deste estágio, o alto estrutural torna-se o principal supridor de material e os rios subsequentes passam a dominar; clastos grossos de leque submarino e leque aluvial então se depositam sobre as fácies de água mais profunda.

As paleocorrentes medidas nos sistemas deposicionais F1, Del e F2 indicam precisamente essas duas fases.O estágio 1 é ilustrado pelas paleocorrentes dos dois primeiros: nas fácies fluviais, as paleocorrentes se dirigem para leste; as deltaicas, com exceção dos canais distributários, têm resultantes para norte ou para sul. Na época de sua deposição não havia correntes vindas do leste. Durante o estágio 2, as paleocorrentes próximo à base do sistema deposicional F2 (em Caeté-Açu e sudoeste de Água de Rega) dirigem-se para os quadrantes norte e sul; as medidas próximo ao seu topo (entre Lençóis e Andaraí e nordeste de Mucugê), refletem o domínio dos rios subsequentes fornecendo elásticos grossos para a admissão lateral dos sedimentos (resultantes para oeste). Dessa forma, a partir das paleocorrentes, pode-se afirmar que o preenchimento da bacia foi iniciado com material vindo do oeste. Desde a deposição do sistema F2, a principal fonte de suprimento de detritos passou a ser o embasamento oriental, com importante contribuição de setores hoje completamente erodidos, da serra de Jacobina.

CONCLUSÕES As litologias, estruturas sedimentares e associações faciológicas descritas para os sistemas deposicionais do Supergrupo Espinhaço na Chapada Diamantina Centro-oriental, tais como arenitos espessos, argilitos, dolomitos com estromatólitos, estratificações cruzadas de grande porte, depósitos fluviais e de maré, são característicos das Associações Q-P-C (Quartzito-Pelito-Carbonato), que de acordo com Condie (1989), compreendem mais de $60 \%$ das rochas supracrustais proterozóicas conhecidas. Os ambientes fanerozóicos onde são encontradas associações semelhantes, são bacias intracratônicas, margens cratônicas de bacias backarc e margens continentais rifteadas (Condie 1989). A análise dos sistemas deposicionais da Chapada Diamantina Centrooriental, identificou o primeiro e o último desses ambientes. A sua evolução tectônica pode ser acompanhada ao longo do tempo geológico pela alternância dos sistemas deposicionais e pela mudança no sentido das paleocorrentes.

Essa evolução começa pela deposição em um rifte (Dl), seguida por subsidência termo mecânica lenta (F1, D2) e implantação de uma margem continental (Del). O fechamento dessa margem em consequência de um evento tectônico é indicada pela mudança no sentido das paleocorrentes (Fig. 22) e pela passagem brusca de sedimentos marinhos para continentais (Del para F2, LA2). A interpretação do sistema deposicional LA2 como erosão de sedimentos transportados sobre rampas indica que o evento tectônico supracitado foi de natureza compressional e seguido por um período de quiescência tectônica, durante o qual o nível do mar subiu, depositando-se então os sistemas de planície de maré (Pm) e marinho plataformal (Mar). Finalmente, a renovação do afluxo terrígeno consequente de novo abaixamento do nível do mar, é representada pelos sistemas deposicionais fluvial (F4) e desértico (D3). Esta evolução sedimentar e tectônica está resumida na figura 23.

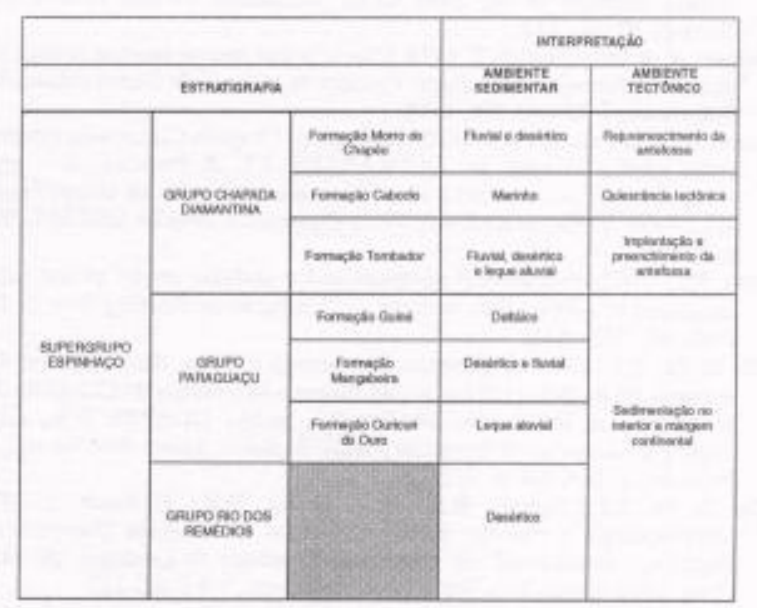

Figura 23 - Estratigrafia, sistemas deposicionais e tectônica do Supergrupo Espinhaço na Chapada Diamantina Centrooriental (modificado de Pedreira 1994b).

Figure 23 - Stratigraphy, de positional systems and tectonics of the Espinhaço Supergroup in the Central-eastern Chapada Diamantina (modified from Pedreira 1994b). 
Abbot, P.L. \& Peterson, G.L. 1978. Effects of abrasion on conglomerate clast populations: Examples from Cretaceous and Eocene conglomerates of San Diego Área, Califórnia. J Sed. Petrol, 48:31-42.

Allen, J.R.L, 1963. The classification of cross-stratified units with notes on their origin. Sedimentology, 2:93-114.

Babinski, M.; Van Schums, W.R.; Chemale Jr., F,; Brito Neves, B.B.; Rocha A.J.D. 1993. Idade isocrônica $\mathrm{Pb} / \mathrm{Pb}$ em rochas carbonáticas da Formacão Caboclo em Morro do Chapéu, BA. In: Simpósio sobre o Cráton do São Francisco, 2, Salvador, 1993. Anais. Salvador, Soe. Brás. Geol/SGM, p.160-163.

Bhattacharyya, A. \& Morad, S. 1993. Proterozoic braided ephemeral fluvial deposits: An example from the Dhandraul Sandstone Formation of the Kaimur Group, Son Valley, Central índia. Sed. Geology, 84:101-114.

Bigarella, J. J. 1975. Lagoa Dune Field, State of Santa Catarina, Brazil - A mode of eolian and pluvial activity. In: International Symposium on the Quaternary, Southern Brazil, 1975. Bol. Paranaense de Geociências, 33: 133-167.

Bomfim, L.F. \& Pedreira, A.J. 1990. Geologia da Chapada Diamantina Oriental, Bahia (Folha Lençóis). In: Bomfim, L.F. \& Pedreira, A.J., Orgs, -Programa de Levantamentos Geológicos Básicos do Brasil. Lençóis (Folha SD.24 V-A-V) Estado da Bahia, Texto Explicativo. Brasilia, DNPM/CPRM, p. $25-73$.

Brookfield, M,E. 1977. The origin of bounding surfaces in ançient aeolian sandstones. Sedimentology, 24:303-332.

Clifton, H.E. 1973. Pebble segregation and bed lenticulary in wave-worked versus alluvial gravel. Sedimentology, 20:173-187.

Condie, K.C. 1989. Plate Tectonics \& Crustal Evolution, 3ed. New York, Pergamon Press, 476p.

Delgado, I.M.; Pedreira,A.J.; Thorman, C.H. 1994. Geology and mineral resources of Brazil: A review. International Geology Review, 36: 503-544

Derby, O.A. 1905. Lavras Diamantinas. Rev. Inst. Geogr. e Hist. da Bahia, 11:143-153.

Deynoux, M.; Duringer, Ph.; Khatib, R.; Villeneuve, M. 1993. Laterally and vertically accreted tidal deposits in the Upper Proterozoic Madina-Kouta Basin, Southeastern Senegal, West Á frica. Sed. Geology, 84:179-188.

Einsele, G. 1992. Sedimentary Basins; Evolution, Fades and Sedimentary Budget. Berlin, Springer-Verlag, 628p.

Eriksonn, K.A. \& Warren, J.K. 1983. A Paleohydrological model for Early Proterozoic dolomitization and silicification Precambrian Res.; 21:299-321,

Fischer, W.L. \& McGowen, J.H. 1967. Depositional systems in the Wilcox Group of Texas and their relationship to occurrence of oil and gas. Gulf Coast Assoe. Geol. Soes. Trans., 17: 105-125.

Galloway, W.E. \& Hobday, D.K. 1983. Terrigenous Clastic Depositional Systems; Applications to Petroleum, Coal, and Uranium Exploration. New York, Springer-Verlag, 423p

Gama Jr., E. 1989. Concepções estratigrafícas em análise de bacias: c) A Estratigrafia genética. Geociências São Paulo, 8:21-36.

Gradzinski, R. 1989. Large scale blowouts in Tumlin Sandstone, Lower Triassic, Poland. In: International Geological Congress, 28, Washington, D.C., 1989. Washington, D.C., Abstracts, v.1, p.1-573.

Gradzinski, R. 1992. Deep blowout depressions in the aeolian Tumlim Sandstone (Lower Triassic) of the Holy Cross Mountains, Central Poland. Sed. Geology, 81:231-242.

Gradzinski, R. \& Jerzykiewics, T. 1974. Dinosaur-and mamal-bearing aeolian and associated deposits of the Upper Cretaceous in the Gobi Desert (Mongólia) Sed. Geology. 12:249-278, 1974.

Guimarães, J.T. \& Pedreira, A.J. 1990. Geologia da Chapada Diamantina Oriental, Bahia (Folha Utinga). In: GUIMARÄES, J.T. \& Pedreira, A.J., orgs. -Programa de Levantamentos Geológicos Básicos do Brasil. Utinga (Folha SD.24-V-A-II) Estado da Bahia, Texto Explicativo. Brasilia, DNPM/CPRM p. $19-92$.

Jackson, R.G. 1975. Hierarchical attributes and a unifying model of bed forms composed of cohesionless material and produced by shearing flow. G.S.A. Bull., 86:1523-1533.

Jardim de Sá, E.F. 1981. A Chapada Diamantina e Faixa Santo Onofre: Um exemplo de tectônica intra-placa no Proterozóico Médio do Cráton do São Francisco. In: INDA, H.; MARINHO, M.M.; DUARTE F.B., Orgs. Geologia e Recursos Minerais do Estado da Bahia; Textos Básicos, vol. IV. Salvador, SME/CPM.p. 111-120.

Jardim de Sá, E.F.; Bartels, R.L.; Brito Neves, B.B.; McReath, I. 1976. Geocronologia e modelo tectonomagmático da Chapada Diamantina e Espinhaço Setentrional. In: Congresso Brasileiro de Geologia, 29, Ouro Preto, 1976. Anais Ouro Preto, Soe. Brás. Geol, v.4 p.205-227.

Kocurek,G. 1981.Significance of interdune deposits and bounding surfaces in aeolian dune sands. Sedimentology, 28:153-180.

Mc Kee, E.D. 1979. Sedimentary structures in dunes. In: Mc KEE, E.D., ed. $A$ Study of Global Sand Seas. USOS Prof. Paper 1052, p. 83-134.

Miall,A.D., 1977. A Review of the braided-river depositional environment. Earth Sei. Reviews, 13: 1-62.
Miall, A.D. 1978. Lithofacies and vertical profile models in braided river deposits: A summary. In: MIALL, A.D., ed. Fluvial Sedimentology. Calgary, Canadian Soe. Petrol. Geol. Mem. 5, p. 597-604

Miall, A.D. 1988. Fácies architecture in clastic sedimentary basins. In: KLEINSPEHN, K. \& PAOLA, C. eds. New Perspectives in Basin Analysis. New York, Springer-Verlag, p.67-81.

Monteiro, M.D · Carvalho, M P · Conceição Filho, V M. 1984 Caracterização faciológica e sistemas deposicionais do Grupo Chapada Diamantina.In: Congresso Brasileiro de Geologia, 33, Rio de Janeiro, 1984. Ana/5. Rio de Janeiro, Soe. Brás. Geol., p.1090-1105.

Montes, A.L.S.; Montes, M.L.; Dardenne, M.A. 1981. A região da Serra de Jacobina, um paleorrelevo ativo durante a sedimentação dos grupos Chapada Diamantina e Bambuí. In: Simpósio sobre o Cráton do São Francisco e suas Faixas marginais, Salvador, 1979 Anais. Salvador, CPM/Soc. Brás. Geol., p.79-86.

Mutti, E. 1992. Turbidite Sandstones. S.Donato Milanese, Agip S.p.A., 275p.

Nikula, R. 1988. Paleosedimentology of Precambrian tidal Virtiovaara and fluvial Varttiovaara quartzite formations in Sodankyla, Northern Finland. Geol. Survey of Finland, Sp. Paper 5: 177-188.

Pedreira, A.J. 1988. Sequências deposicionais no Precambriano: Exemplo da Chapada Diamantina Oriental. In: Congresso Brasileiro de Geologia, 35 , Belém, 1988. Anais. Belém, Soe. Brás. Geol., v. 2, p.648-659.

Pedreira, A.J. 1989. Sistema desértico do Grupo Paraguaçu (Proterozóico Médio) na região da Chapada Diamantina, Bahia. In: Simpósio de Geologia do Nordeste, 13/Simpósio Nacional de Estudos Tertônicos, 2, Fortaleza, 1989. Atas, Fortaleza, Soe. Brás. Geol., (Boletim n_. 11) p.139-141

Pedreira, A.J.1994a. The Mid-Proterozoic Lavras conglomerate: evidence of thin skinned tectonics in the Chapada Diamantina, Brazil. In: International Sedimentological Congress, 14, Recife, 1994. Abstracts, Recife, Int. Assoe. Sed., p. G 61-62

Pedreira, A.J.1994b. O Supergrupo Espinhaço na Chapada Diamantina Centro-oriental, Bahia: Sedimentologia, Estratigrafia e Tectônica. São Paulo, USP, Instituto de Geociências. Tese de Doutoramento, 126p. (inédita).

Pedreira, A.J.1995. Estratigrafia de sequências e modelo deposicional da Formação Guiné (Mesoproterozóico) na Chapada Diamantina, Bahia. In: Simpósio de Geologia de Minas Gerais, 8, Diamantina, 1995. Anais. Diamantina, SBG, p. 28-29 (Boletim no. 13).

Pedreira, A.J.; Dossin, I.A.; Uhlein, A.; Dossin, T.M.; Garcia, A.J.V. 1989. Kibaran (Mid-Proterozoic) evolution and mineralizations in Eastern Brazil. IGCP 255 Newsletter, 2:57-63.

Pedreira, A.J.. \& Margalho, R.S.F.X. 1990. Geologia da Chapada Diamantina Oriental, Bahia (Folha Mucugê). In: Pedreira, A.J.. \& Margalho, R.S.F.X.; Orgs., Programa de Levantamentos Geológicos Básicos do Brasil. Mucugê (Folha SD.24-V-C-I1), Estado da Bahia; Texto Explicativo. Brasília; DNPM/CPRM, p.19-68.

Ricci Lucchi, F, 1985. Influence of transport processes and basin geometry on sand composition. In: Zuffa, G., ed., Provenance of Arenites. Dordrecht, D. Reidel,p.19-45

Ross, G.M. 1983. Proterozoic aeolian quartz arenites from the Hornby Bay Group, Northwest Territories, Canada: Implications for Precambrian aeolian processes. Precambrian Res., 20:149-160.

Rust, B.R. 1978. Depositional models for braided aluvium. In: Miall, A.D., ed.. Fluvial Sedimentology. Calgary, Can. Soe. Petrol. Geol., Mem. 5, p.605-626.

Souza, W.S.T. \& Guerra, G.T. 1986. Estudo geológico da Chapada Diamantina-Setentrional a partir do emprego do conceito de unidade deposicional. In: Congresso Brasileiro de Geologia, 34, Goiânia, 1986. Anais. Goiânia, Soe. Brás. Geol., vol. 1, p.377-390.

Strand, K. 1988. Alluvial sedimentation and tectonic setting of the Early Proterozoic Kurkikyla and Kainuu Groups in Northern Finland. Geol. Survey of Finland Sp. Paper 5, p.75-90.

Tankard, A.J.; Hobday, D.K.; Jackson, M.P.A.; Hunter, D.R.; Eriksson, K.A.; Minter, W.E.L. 1982. Crustal Evolution of Southern Africa - 3.8 Billion Years of Earth History. New York, Springer-Verlag, 523 p.

Tucker, M.E. 1982. The Field Descripíion of Sedimentary Rocks. Milton Keynes, The Open University Press, 112p. (Geol. Soe. London Handbook Series).

Vilas Boas, G,; Pereira, A.M. \& Sampaio, F. 1988. Fácies sedimentares e modelo de sedimentação do Grupo Paraguaçu na região de Rio de Contas, borda ocidental da Chapada Diamantina, Bahia. Rev. Bros. Geoc., 18:406-416.

Walker, T.R. 1979. Red color in dune sand. In: McKee, E.D., ed. A Study of Global Sand Seas. USGS Prof. Paper 1052, p. 61-81.

Manuscrito A859

Recebido em 20 de outubro de 1996

Revisã o dos autores em 22 de dezembro de 1997 Revisã o aceita em 23 de dezembro de 1997 